Board of Governors of the Federal Reserve System

International Finance Discussion Papers

Number 546

March 1995

RETURNS TO SCALE IN U.S. PRODUCTION: ESTIMATES AND IMPLICATIONS

Susanto Basu and John G. Fernald

NOTE: International Finance Discussion Papers are preliminary materials circulated to stimulate discussion and critical comment. References in publications to International Finance Discussion Papers (other than an acknowledgment that the writer has had access to unpublished material) should be cleared with the author or authors. 


\begin{abstract}
A typical (roughly) two-digit industry in the United States appears to have constant or slightly decreasing returns to scale. Three puzzles emerge, however. First, estimates tend to rise at higher levels of aggregation. Second, estimates of decreasing returns in many industries contradict evidence of only small economic profits. Third, estimates using value added differ substantially from those using gross output, and appear less robust. These puzzles are inconsistent with a representative firm paradigm, but are consistent with simple stories of aggregation over heterogeneous units. We discuss implications of this heterogeneity for recent models of imperfect competition in macroeconomics.
\end{abstract}




\title{
RETURNS TO SCALE IN U.S. PRODUCTION: ESTIMATES AND IMPLICATIONS
}

\author{
Susanto Basu and John G. Fernald'
}

Why is productivity procyclical? That is, why do measures of labor productivity and total factor productivity rise in booms? The answer to this question sheds light on the relative merits of different models of business cycles. One recent class of explanations emphasizes the potential role of imperfect competition and increasing returns to scale. Measured total factor productivity then reflects not just technology shocks, but also variations in input use. Robert Hall $(1988,1990)$, especially, has argued that relaxing the traditional assumptions of perfect competition and constant returns helps explain procyclical productivity.

In addition, recent papers show that increasing returns and imperfect competition can modify and magnify the effects of various shocks in an otherwise standard dynamic general equilibrium model. In response to government demand shocks, for example, models with countercyclical markups can explain a rise in real wages while models with increasing returns can explain a rise in measured productivity. Perhaps most strikingly, if increasing returns are large enough, they can lead to multiple equilibria, in which sunspots or purely nominal shocks drive business cycles. ${ }^{2}$

'The authors are respectively: Assistant Professor of Economics at the University of Michigan and Faculty Research Fellow of the National Bureau of Economic Research; and Staff Economist in the Division of International Finance, Board of Governors of the Federal Reserve System. Please address correspondence to S. Basu, Department of Economics, University of Michigan, 611 Tappan St., Ann Arbor, MI 48109-1220; or J. Fernald, Mail Stop 20, Federal Reserve Board, Washington, DC 20551..

This is a substantially revised version of a paper previously circulated as "Constant Returns and Small Markups in U.S. Manufacturing." We thank Russ Cooper, Dale Jorgenson, Sam Kortum, Greg Mankiw, Stephanie Schmitt-Grohé, and an anonymous referee for helpful comments, and Barbara Fraumeni for help with the data. We particularly thank Mike Woodford for extensive written comments on an earlier version of this paper. Basu is grateful to the National Science Foundation for financial support and to the Hoover Institution for its hospitality. This paper represents the views of the authors and should not be interpreted as reflecting the views of the Board of Govemors of the Federal Reserve System or other members of its staff.

2 See, for example, Rotemberg and Woodford (1992), Farmer and Guo (1994), and Beaudry and Devereux (1994). For a survey of dynamic general equilibrium models with imperfect competition, see Rotemberg and Woodford (1995). 
In assessing the merits of these models, one thus needs to know the empirical importance of increasing returns and imperfect competition. In particular, some models offer predictions that differ significantly from those of more standard models only with substantial increasing returns and a high degree of imperfect competition. Indeed, in some cases new results only exist with sufficiently large increasing returns (e.g. Farmer and Guo 1994). Are these models merely intellectual curiosities, or do they provide genuine insight into the macroeconomy?

This paper provides new empirical evidence on the importance of deviations from constant returns and perfect competition. Using data on 34 industries that together constitute the U.S. private business economy, including 21 roughly two-digit manufacturing industries, we estimate that a typical industry has constant or even decreasing returns to scale, implying at most small markups of price over marginal cost. This finding contrasts with Hall (1990) and Domowitz, Hubbard and Petersen (1988), for example, whose estimates suggest large increasing returns. We find substantial heterogeneity across sectors, however, with durable manufacturing industries showing some evidence of increasing retums, and non-durable industries showing some evidence of decreasing returns. Moreover, this heterogeneity turns out to have cyclical implications, so that neither industries nor aggregates behave as if they were single firms.

In particular, aggregation potentially explains three puzzles in the data. First, a typical industry appears to have significantly decreasing returns to scale. In the absence of large pure profits, decreasing returns at a firm level implies that firms consistently price output below marginal cost, which obviously makes no economic sense. Second, point estimates vary with the level of aggregation, with a typical industry showing apparent decreasing returns, but total manufacturing and the total private economy showing apparent increasing returns. ${ }^{3}$ Third, value-added estimates differ substantially from gross-output estimates, and appear less robust. Value added is not a natural measure of output, and can in general only be interpreted as such with perfect competition. With imperfect competition, the use of value added, even at a firm level, suffers from an omitted variable bias; in addition, value added suffers different aggregation biases than gross output. A priori, we cannot say whether aggregation biases âre larger for value added

3 Caballero and Lyons (1992) observed the difference in estimates of returns to scale at different levels of aggregation but interpreted this as evidence of productive spillovers across industries; we argue that aggregation bias provides a better explanation. 
or for gross output. but as an empirical matter it appears that aggregation biases can explain the lack robustness in empirical estimates using value-added data.

Much of the difficulty in providing simple estimates of returns to scale arises from the substantial heterogeneity in the data. Macroeconomic theory provides relatively little guidance for dealing with heterogeneity, since most models assume identical firms. How, then, does heterogeneity affect macroeconomic models? Consider three uses of fully-specified models. First, they serve as parables-simple but precisely-told stories illustrating a particular economic mechanism. Second, they help in understanding the sources of economic fluctuations, particularly by matching key moments in economic data. Third, they are laboratories used to study the effects of particular policy interventions.

The importance of heterogeneity in production differs in each of these uses. For the model qua parable, one can probably, with little cost, abstract from heterogeneity if the point is to explore other economic mechanisms. For example, that production takes place at heterogeneous plants is probably irrelevant for making the point that intertemporal substitution in labor supply is an important propagation mechanism in business-cycle models.

But the abstraction may be more costly when one seeks to understand business cycles or predict the effects of policy changes. We make this point with a simple, highly stylized model. In one case, despite heterogeneity, the aggregate degree of returns to scale (which exceeds the average firm's returns to scale) is a sufficient statistic for understanding and calibrating the model. In the second case, this summary statistic does not suffice. The example economies differ only in non-production institutions. Hence, general results appear unlikely: The importance of heterogeneity depends on particular features of the model.

Section I extends existing firm-level theory estimating returns to scale. We review Hall's simple non-parametric method, and relate two concepts of returns to scale used in macroeconomic studies-returns to scale in gross output and value added. Section II makes the common macroeconomic assumption that industries and aggregates can be modeled as firms. We identify three puzzles, which lead to our proposed solution in Section III: Because of aggregation effects, neither industries nor aggregates can costlessly be modeled as individual firms. Section IV controls empirically for aggregation effects in moving from our industries to various aggregates, demonstrating the importance of these effects. In 
Section V, we reflect on the implications of our results for calibrating macroeconomic models. Section VI concludes.

\section{Estimating Firm-Level Returns to Scale ${ }^{4}$}

In this section we quickly review and generalize Hall's (1990) method for estimating returns to scale. We then relate estimates of returns to scale from gross output data to those from value-added data, and evaluate the potential biases from using value added as a measure of production.

\section{A. Methods for Estimating Returns to Scale}

At a firm level, the correct model of production relates gross output, $Y$, to primary inputs of capital, $K$, and labor, $L$, as well as purchased intermediate inputs of materials and energy, $M$. Letting $T$ denote the state of technology, we write the firm's production function as:

$$
Y=F(K, L, M, T) \text {. }
$$

We define $s_{J}$ as the share of costs for input $J$ in total revenue, and $c_{J}$ as the share in total cost. We assume that firms are price takers in factor markets. Cost minimization then implies that the growth rate of output dy equals returns to scale $\gamma$ multiplied by the cost-share-weighted growth in inputs $\mathrm{dx}$, plus gross-outputaugmenting productivity growth $\mathrm{dt}$. That is, if $\mathrm{dl}$, $\mathrm{dk}$, and $\mathrm{dm}$ are the growth rates of $\mathrm{L} K$, and $\mathrm{M}$, then

$$
\begin{aligned}
d y & =\gamma \cdot\left[c_{L} d l+c_{K} d k+\left(1-c_{L}-c_{K}\right) d m\right]+d t \\
& \equiv \gamma \cdot d x+d t .
\end{aligned}
$$

This equation generalizes Hall (1990, equation 5.29). Hall's equation, in turn, generalizes the equation defining Solow's residual, allowing for both non-constant returns and the possibility of economic profits.

Cost minimization implies that returns to scale $\gamma$ equals the ratio of average to marginal cost. Increasing returns can take different forms, e.g., no fixed costs but diminishing marginal cost; or fixed costs with flat or upward sloping marginal cost. Once we estimate $\gamma$, we can also calculate a corresponding markup of price over marginal cost, $\mu$. An identity links returns to scale and the markup: We calculate an average profit share $s_{n}$ from our series on the required retum to capital, which we need

4 Appendix I derives the equations in this section in greater detail. 


$$
\gamma=\frac{A C}{M C}=\left(\frac{P}{M C}\right) \cdot\left(\frac{A C}{P}\right)=\mu \cdot\left(1-s_{\pi}\right) .
$$

to construct the cost shares in (2); an estimate of $\gamma$ then implies an estimate of $\mu$. We estimate an average profit rate of at most 3 percent. ${ }^{5}$ Hence, given relatively small profits, equation (3) shows that $\mu$ approximately equals $\gamma$; large markups, for example, require large increasing returns.

Given low estimated profits, equation (3) also shows that strongly diminishing returns imply firms consistently price output below marginal cost. Since this implication makes no economic sense, we conclude that firm-level returns to scale must either be constant or increasing.

The natural model of production at the firm level uses gross production as the concept of output and explicitly models the use of materials input, as in equation (2). However, Hall and many subsequent authors instead relate value added to primary inputs of capital and labor alone. We discuss the relative merits of this choice later. For now we simply note the Divisia definition of real value added: ${ }^{6}$

$$
d v \equiv \frac{\left(d y-s_{M} d m\right)}{\left(1-s_{M}\right)}=d y-\left(\frac{s_{M}}{1-s_{M}}\right)(d m-d y) .
$$

Value added is like a partial Solow residual, subtracting intermediate growth from output growth, weighted by the share of intermediate inputs in revenue. The second equality shows that if the materialsto-output ratio is constant, then value added grows at the same rate as gross output and intermediates.

The cost-weighted measure of primary input growth, $\mathrm{dx}^{\mathrm{v}}$, is defined analogously to $\mathrm{dx}$, so that $\mathrm{dx}^{\mathrm{v}}$ equals $\left(c_{K} d k+c_{L} d l\right) /\left(c_{K}+c_{\nu}\right)$. Thus, the equation estimated by Hall (1990) and others is:

$$
d v=\rho \cdot d x^{v}+v .
$$

As in equation (2), the error term is interpreted as a shock to production technology. We discuss the relationship between $\rho$ and $\gamma$ below.

s Rotemberg and Woodford (1995) also provide a variety of evidence suggesting that profit rates are close to zero.

- Beginning in 1995, the U.S. National Income and Product Accounts measure real GDP and sectoral real value added as chain-linked Fisher indices. Chain-linked Fisher indices are one discrete-time approximation of the continuous-time Divisia definition used here. 


\section{B. Value Added as a Measure of Production}

Why do macroeconomists often use value-added data? A compelling reason is that macroeconomists are typically interested in understanding value-added aggregates, especiaily GDP. Summed across firms or industries, real value added has the desirable property of equalling total national expenditure. Thus, aggregate value added is clearly appropriate for focusing on the uses of output. But as we now discuss, value added is not generally appropriate for studying productivity growth, attempting to understand the sources of output change, since it is not in general a valid production measure.

Gross-output returns to scale $\gamma$ and markup $\mu$ are the primitives of technology and behavior. Thus, they are conceptually the natural parameters for, say, calibrating multi-sector models with imperfect competition. On the other hand, as we now demonstrate, value-added data generally yield biased estimates of returns to scale in the presence of imperfect competition. To show this, rewrite equation (2) as:

$$
d y=\gamma\left(1-c_{m}\right) d x^{\nu}+\gamma c_{M}+d t .
$$

Then, using definition (4), the definition of $\mathrm{dx}^{\mathrm{v}}$, and the first-order condition for cost-minimization that $\gamma c_{m}=\mu s_{M}$, we find:

$$
d v=\left[\frac{\gamma \cdot\left(1-c_{M}\right)}{1-\gamma \cdot c_{M}}\right] \cdot d x^{\nu}+(\mu-1)\left[\frac{s_{M}}{\left(1-\mu s_{M}\right)\left(1-s_{M}\right)}\right] \cdot(d m-d y)+\frac{d t}{1-\gamma c_{M}} .
$$

Thus, equation (5) is generally misspecified: There is an omitted variable in the estimating equation that uses value added as the output measure. This variable is identically zero in two cases: if there is perfect competition, so that price equals marginal cost; or if the elasticity of substitution between materials and other inputs is zero. so that $\mathrm{dm}$ equals $\mathrm{dy}$. Since $\mu \geq 1$, the coefficient multiplying (dm-dy) is weakly positive. So the sign of the omitted-variable bias depends on the sign of the covariance between the projection of $d x^{v}$ on the instruments and (dm-dy). If materials intensity is procyclical, the bias is positive.

Suppose for the moment that the bias is zero. Then equation (7) shows that $p$ in equation (5) estimates $r(1-\mathrm{cm}) /(1-\gamma \mathrm{cm})$. Making further assumptions about technology provides some economic intuition for this quantity. Suppose the production function (1) takes the following separable form:

$$
Y=G\left(V^{P}(K, L, T), H(M)\right) \text {. }
$$

Following the logic used to derive equation (2), we can write the growth of productive value added $d^{p}$ 
in terms of the cost-weighted growth in primary inputs $\mathrm{dx}^{\nu}$, plus technology shocks (without loss of generality we normalize to one the elasticity of productive value added $V^{p}$ with respect to technology):

$$
d v^{p}=\gamma^{v} d x^{v}+d t^{v} .
$$

$\gamma^{\vee}$ equals the sum of elasticities of $\mathrm{V}^{\mathrm{P}}$ with respect to capital and labor. We cannot, in general, make any statements about the magnitude of this parameter. To do so, we make the further substantive assumption that all returns to scale are in $\mathrm{V}^{\mathrm{P}}$, arising perhaps from overhead capital or labor. This requires that $G$ be homogeneous of degree one in $\mathrm{V}^{\mathrm{p}}$ and $H$, and that $H$ be homogeneous of degree one in $M$. The sum of output elasticities with respect to all inputs is $\gamma$, which in turn is the sum of $\left(1-\gamma c_{M}\right)$ and $\gamma c_{M}$. Hence, the relationship between $\gamma$ and $\gamma^{v}$ is

$$
\gamma^{\nu}=\gamma \cdot\left(\frac{1-c_{M}}{1-\gamma c_{M}}\right) .
$$

Thus, $\rho$ corresponds to $\gamma^{v}$, the parameter often of interest to macroeconomists. For example, if $G$ is Leontief in $\mathrm{V}^{\mathrm{p}}$ and $H$, then in a representative-firm model $\gamma^{\mathrm{V}}$ equals returns to scale of the economy's aggregate production function for GDP.? If the materials-to-output ratio is acyclical (and hence orthogonal to $\mathrm{dx}^{\mathrm{v}}$ ), then using value-added data provides an unbiased estimate of $\gamma^{\mathrm{v}}$. Of course, without any assumptions about the materials-to-output ratio, one can estimate a gross output $\gamma$, then calculate the implied $\gamma^{\prime}$ from equation (10).

\section{How Large is "Large"?}

To provide context for our results, we briefly discuss how large deviations from constant returns and perfect competition need to be to generate new results. We focus our discussion on $\gamma^{v}$ and its

7 Rotemberg and Woodford (1995). Basu (1995a) explores some of the implications of dropping the assumption that $G$ is Leontief. Note that the data do not support the assumption of a zero elasticity of substitution. Bruno (1984) reviews a number of studies and concludes that the elasticity is between 0.3 and 0.4. Rotemberg and Woodford (1993, Appendix III) conclude that a reasonable value for this elasticity is 0.7 . 
corresponding value-added markup. ${ }^{8}$

Countercyclical markups generally magnify the effects of imperfect competition and increasing returns. In a model with implicit collusion and countercyclical markups, for example, Rotemberg and Woodford (1992) find that a steady-state markup of 1.2 suffices to establish a qualitatively new result: Real wages rise when government purchases rise, since falling markups shift out the labor demand schedule. Thus, reiatively smail deviations from constant returns and perfect competition can significantly change model predictions.

For many recent models of indeterminacy, however, striking results exist only with sufficiently large markups and returns to scale. Schmitt-Grohé (1995) explores the calibration of four prominent models of indeterminacy and finds the minimum values of $\gamma^{\vee}$ that transform the steady state of the neoclassical growth model into a sink rather than a saddlepoint, so that "animal spirits" matter in a rational-expectations equilibrium. Models with a constant markup, such as that of Farmer and Guo (1994), typically require markups in excess of 1.75 . Even a model with countercyclical markups requires markups in excess of 1.4. (Schmitt-Grohé emphasizes, however, that these minimums unrealistically assume an infinite labor supply elasticity and a labor cost share of 0.7 ).

This question of "how large is large" can only be answered in a specific model. Hence, while existing models provide a benchmark for interpreting our empirical results, our results also provide an input into the development of "reasonable" models. Some recent models, for example, incorporate features to get indeterminacy in ways that do not require sizeable increasing returns. For example, multi-sector models can generate indeterminacy with relatively smal! increasing returns, essentially because each sector faces downward-sloping supply curves for capital and labor even if aggregate factor supplies are increasing functions of factor prices and are quite inelastic. ${ }^{9}$

${ }^{8}$ Most existing models assume the existence of a representative producer whose production function satisfies the conditions in equation (8), with zero elasticity of substitution between $V$ and $M$. Since profits are small, calibration in terms of returns to scale or markups are roughly equivalent, so we use the terms interchangeably.

${ }^{9}$ Benhabib and Farmer (1995), and Perli (1995). 


\section{Data and Puzzling Results}

We now apply the theory from Section I to estimate returns to scale in U.S. production at various levels of aggregation. We follow the standard macroeconomic practice of applying firm-level theory to relatively aggregated data: within manufacturing, for example, our industries are approximately two-digit SIC. We use aggregates, rather than firms, since comprehensive firm-level data exist for only narrow sectors of the U.S. economy. Even in manufacturing, where relatively detailed data are available, time series data on firms are incomplete, of short duration, and ignore entry and exit.

But applying firm-level theory to aggregate data produces three puzzling results: Returns-to-scale estimates differ at different levels of aggregation; estimated returns to scale are sometimes strongly diminishing; and results are too sensitive to the use of gross output versus value added. We document these puzzles here and attempt to resolve them in the following sections of the paper.

\section{A. Data}

We use data provided by Dale Jorgenson for 34 industries that together constitute the U.S. private business economy for 1959-1989. These data seek to provide complete sectoral production data, and represent a massive effort to ensure consistency with production theory. Hence, the dataset contains observations on primary and intermediate inputs as well as gross output. Jorgenson, Gollop and Fraumeni (1987) document the data thoroughly.

Appendix II describes in greater detail how we use the data. In brief, we construct several variables from the data. First, for each industry we calculate output and input growth rates as log changes. Second, we calculate payments to capital by estimating capital's user cost, as in Hall (1990). Third, we calculate Divisia aggregates of output and input growth at the level of non-durable, durable, and total manufacturing, as well as the total private business economy. Fourth, we construct value-added data for each industry and aggregate using definition (4). ${ }^{10}$

We present regressions both instrumented and uninstrumented. Hall (1990) argues for demandside instruments; he uses changes in the world price of oil and government defense spending, and the

${ }^{10}$ A previous version of this paper also used the Hall dataset. The qualitative features of our results do not change much with that dataset-the puzzles we document remain. 
political party of the President. For comparability, we use these instruments along with one lag of each.

In later sections, however, we emphasize the uninstrumented results, for two reasons. First, the instruments may not be completely exogenous, uncorrelated with the disturbance term. For example, for value added. equation (7) shows that anything that changes the intensity of intermediate input use (as oil prices may) is not a valid instrument. For gross output, as well, if technological change is energy-biased then lower oil prices are associated with faster technology growth. More importantly, we argue in Section IV that aggregation effects appear important in the data, and that these effects are correlated with aggregate-demand shocks. Second, our instruments are relatively weakly correlated with inputs for some industries. Even if the instruments are not so weak that they lead to small-sample problems (such as those pointed out by Nelson and Startz (1990) and Staiger and Stock (1994), among others), instruments that are both relatively weak and potentially correlated with the disturbance term suggest that IV may be more biased than OLS."

\section{B. Results}

Tables 1 and 2 report our estimates from equations (2) and (5). Table 1 reports single-equation estimates using data at various levels of aggregation; Table 2 reports weighted averages of the results of similar regressions for the industries that comprise those aggregates. In both tables, the first line reports estimates of $\gamma$ from gross-output data. The second line uses equation (10) to convert these gross-output estimates to estimates of $\gamma^{v}$. The third line reports estimates of $\rho$ (which may or may not be good estimates of $\gamma^{\prime}$ ) using our constructed measures of value added. The top panel shows two-stage least squares; the bottom panel shows OLS.

In Table 2, for example, the first column is the weighted average of results for all 34 individual industries. The weights are the shares of each industry in the aggregate. In the first row, the weights are in total nominal gross output; in the second and third rows, the weights are in total nominal value added. Note that the second row of Table 2 is not a simple transformation of the estimate in row one, since $\gamma^{v}$

i The first-stage F-statistic averages about 3. Whether or not we instrument does not affect our qualitative results, and usually has only a small effect on our quantitative results. We cannot tell whether this invariance reflects small OLS bias or weak/invalid instruments. 
is calculated for each industry before averaging. ${ }^{12}$

Beginning with the instrumented results in Table 1, the first line shows that gross output in the total private economy as well as non-durables manufacturing show statistically significant evidence of aggregate increasing returns. Within manufacturing, durables shows the strongest evidence of increasing returns. As shown in row 2, the magnitude of increasing returns is sizeable: For the entire private economy. the estimate of $\gamma^{\vee}$ is 1.72 -taken at face value, this estimate is large enough to justify some existing models of multiple equilibria. Even the estimate for durables manufacturing, 1.46, is capable of justifying multiple equilibria in some models.

Given questions about the instruments, the bottom panel shows the regressions uninstrumented. The point estimates are, for the most part, little changed; the point estimates are (surprisingly) lower uninstrumented for the entire economy, as wel! as for durables. Point estimates generally rise for durables. The major effect is on standard errors. Uninstrumented, we can now reject constant returns at the 1 percent level for total manufacturing gross output.

Comparing Tables 1 and 2 documents our first puzzle: Estimated returns to scale are strikingly larger in aggregate than in industry-level data. In Table 2, only durable-goods manufacturing industries show any evidence of increasing returns to scale. Even there, the point estimate for $\gamma^{v}$ is only 1.28 ; applying this estimate to the entire economy would be large enough to give some interesting macroeconomic results but would not generate multiple equilibria in most models. For manufacturing overall, the typical industry has diminishing returns to gross output, while the typical industry has roughly constant returns in value added production (row 2). For the entire economy, returns to scale appear strongly diminishing, particularly using value-added data. In non-durables, retums to scale are particularly diminishing by any measure.

This finding constitutes our second puzzle: Returns-to-scale estimates are often much smaller than

12 We convert each estimate of $\gamma$ to $\gamma^{\vee}$ using the sample average $c_{M}$ for the corresponding industry or aggregate. Standard errors are calculated by linearizing equation (10) and using the standard variance formulas for linear equations. For the weighted averages, standard errors are calculated assuming the estimates are independent, and using the standard formula for the variance of a sum of random variables. Estimating the system of equations for manufacturing using SUR (allowing for different parameters for each industry) would allow for non-zero covariances in the estimates; this makes only a small difference to the standard errors of the weighted average, however, on the order of 0.01 . 
one. Returns to scale are larger in the instrumented regressions (opposite what we expect if the problem is positive feedback technology shocks to input use), but even there, where the average value of $\gamma^{\mathrm{v}}$ is $\mathbb{f} .16$ for the entire private economy, the median estimate (not shown) is 1.01 . Hence, half the estimates are less than one. (Statistically, five individual estimates are significantly less than one at the 5 percent level; three are significantly greater than one.) As noted in our discussion following equation (3), strongly diminishing retums imply sizeable economic profits, which are not observed in U.S. data. Furthermore, the possibility of replication suggests that in the long run, marginal cost should not much exceed average cost. We thus believe a priori that returns to scale should be no lower than constant - but the data seem to contradict us.

Our third puzzle comes from comparing our gross-output and value-added results. In Table 1, the point estimates using value-added data are consistently smaller than the implied $\gamma^{\vee}$ from the gross-output estimates, and standard errors are large enough that we can never reject constant returns in the instrumented regressions. The most striking estimate is for manufacturing non-durables, where the point estimate suggests returns to scale of about zero. (The standard error is so large, however, that the regression is largely uninformative.) Table 2 shows a similar pattern.

Equation (7) showed that value-added estimates suffer a potential omitted-variable bias: Can this bias explain the differences between gross-output and value-added estimates of $\gamma^{\mathrm{v}}$ ? The bias should depend on the regression coefficient of the omitted variable, $(\mathrm{dm}-\mathrm{dy})$, onto $\mathrm{dx}^{\mathrm{v}}$, suitably instrumented. For 22 of the 34 industries, the coefficient is positive, averaging about 0.1 . For all of our aggregates, as well, the coefficient is positive. Since a priori the markup is greater than or equal to 1 , equation (7) implies that value-added estimates should be biased upwards.

In Tables 1 and 2, however, direct value added estimates tend to be smaller than the indirect gross output estimates. Thus, the firm-level theory that predicts differences between these two estimates does not explain the differences we actually find. ${ }^{13}$

The results in Tables 1 and 2 thus leave us with three puzzles. First, the aggregate results differ

13 With heterogeneity, Jensen's inequality also implies that line two should yield smaller estimates than line 3, since equation (10) is convex. Thus, heterogeneity heightens the puzzle of why gross output and value added estimates of $\gamma^{v}$ differ. 
significantly from the sectoral results, tending to show increasing returns. Second, the weighted average of sectoral estimates in Table 2 often show a statistically significant degree of diminishing returns to scale. Third, results are too sensitive to whether they are estimated from gross output or value added. The rest of this paper attempts to resolve these puzzles.

\section{Comparison with existing literature}

Consistent with our findings, previous literature reports a wide range of returns to scale estimates, depending on type of data, level of aggregation, and estimating method. First, several widely cited papers find sizeable industry increasing returns or markups. Hall (1990), for example, reports large increasing returns using data for two-digit manufacturing value added, while in Table 2 we report decreasing returns with similar data. This difference arises primarily because Hall estimates equation (6) in reverse, regressing input growth on output growth, then inverting the resulting coefficient. In our data, the reverse regressions almost always show strong and statistically significant increasing returns as well.

The reverse regressions are not trustworthy, however. The OLS bias is large, since output (the right-hand-side regressor) necessarily covaries with disturbances to output. Instrumental variables do not necessarily eliminate the resulting bias, for two reasons. First, the literature on the smal!-sample properties of IV suggest that if OLS bias is large, the instruments must be relatively strongly correlated with the endogenous explanatory variable; otherwise, IV estimates are biased in the direction of the OLS bias. Bartelsman (1995) presents Monte Carlo evidence suggesting that the resulting small-sample bias of the reverse regressions is severe. Second, if the instruments are not only weak, but are bad (correlated with the error term), then the resulting bias is likely to be larger in the reverse regression. This bias depends on the covariance between the disturbance term and the fitted value of the endogenous explanatory variable; with bad instruments, the fitted value for output necessarily covaries with the disturbance term. In Section IV, we argue that the instruments are bad. Putting output on the right-hand side of the regression thus puts very strong and probably unwarranted faith in the explanatory power and exogeneity of the instruments; the forward regression follows more naturally from theory, and suffers fewer econometric problems.

Domowitz, Hubbard, and Petersen (1988) use four-digit gross output data and report gross-output 
markups of around 1.6. We find their results implausible, largely because their data are incomplete in ways that make their productivity residuals spuriously cyclical. Perhaps most importantly, their labor compensation data are incomplete, omitting FICA, health insurance, and pensions, for example. As a result, labor's share of value added is only about one-third (see Norrbin 1993); since labor hours are much more cyclical than the capital stock, measured productivity becomes more cyclical than true productivity.

Second, some other recent work at the industry level also finds the puzzle of decreasing returns. For example, Burnside (1995) explores the robustness of our industry results across data sets, instrument iists, and sample periods. Úsing Hall's manufacturing value-added data for $1953-84$, he reports a weighted-average returns to scale of about 0.9. Burnside, Eichenbaum, and Rebelo (1995) use several data sets; in quarterly three-digit manufacturing data, for example, they report estimates of $\gamma^{v}$ between 0.8 and 0.9. (In some, though not all specifications, the results are statistically less than one. See their Table 5.)

Third, several authors argue that procyclical productivity and apparent increasing returns result from cyclical variations in the intensity of input use, resulting for example from labor hoarding. ${ }^{14}$ In this paper we take no account of cyclical variations in capacity utilization, even though we do not doubt that such variations exist. Such variations cannot, however, explain our three puzzles. First, they explain apparent increasing returns, not the apparent decreasing returns found in the industry data. Second, they cannot explain the difference between industry and aggregate estimates, since capacity utilization explains apparent aggregate increasing returns by explaining apparent industry (and firm) increasing returns. Third, variations in intensity of capital and labor use affect both value added and gross output regressions in the same direction, and cannot account for different results with different data. (In practice, attempts to control for capacity utilization usually have surprisingly little effect on returns to scale estimates. For example, Burnside (1995) tries to use energy use to control for variations in capital utilization; his estimate of the weighted-average gross-output returns to scale rises from 0.87 to 0.91 .)

Fourth, most plant and engineering studies find essentially constant returns to scale. For example, Baily, Hulten, and Campbell (1992) use plant-level data and find about constant returns, with more estimates slightly below 1 than above. Griliches and Ringstad (1971) argue that essentially constant

it See, for example. Bils and Cho (1994), Burnside, Eichenbaum and Rebelo (1995) and Basu (1995c). 
returns are needed to rationalize the observed large dispersion of establishment sizes within a given industry.

Finally, Caballero-Lyons (1992) first noted the puzzle that returns to scale rise at higher levels of aggregation. They interpreted this as evidence of enormous productive spiliovers across industries. However, we do not find their explanation compelling. First, it is hard to identify specific examples of such spillovers affecting manufacturing plants. Second, Basu and Fernald (1995a) find that the CaballeroLyons specification, which involves including aggregate inputs in industry regressions, shows apparent externalities in value-added data, but not in gross-output data. If these are true productive spillovers, the effect should be present in both sources of data. Thus, we confirm their stylized fact in our data, but are not convinced by their explanation.

\section{Aggregating Over Firms}

Macroeconomics is microeconomics plus aggregation. ${ }^{15}$ The previous two sections focused on microeconomics, asking how far one can take the representative-firm paradigm. We concluded that the data seem inconsistent with firm-level theory. This section focuses on aggregation, asking when it matters that each of our industries comprises thousands of firms.

We aggregate gross output and value added as Divisia indices. Thus, aggregate gross output growth dy and value-added growth $d v$ are:

$$
\begin{aligned}
& d y=\sum_{i} w_{i} \cdot d y_{i} \\
& d v=\sum_{i} w v_{i} \cdot d v_{i} .
\end{aligned}
$$

where $w_{i}$ is the share of the firm's revenue in total industry revenue and $w v_{i}$ is the share of the firm's nominal value added (revenue minus intermediate-input costs) in total industry value added.

We assume that there are no economic profits (so total cost equals total revenue), and that factor

15 Fisher (1993). 
markets are perfectly competitive. ${ }^{16}$ These assumptions imply that the growth of industry inputs, $d x$, equals the weighted sum of firm-level inputs $d_{x_{i}}$ :

$$
d x=\sum_{i} w_{i} \cdot d x_{i}
$$

Substituting into equation (11) for the growth rates of $d y_{i}$, we find:

$$
d y=\sum_{i} w_{i} \gamma_{i} \cdot d x_{i}+\sum_{i} w_{i} d t_{i}
$$

Defining $\bar{\gamma}$ as the weighted-average returns to scale in the industry, $\sum w_{i} \gamma_{i}$, we can rewrite this as

$$
d y=\bar{\gamma} d x+R+d t,
$$

where dt equals the weighted average of firm technology shocks, and

$$
R=\sum_{i} w_{i}\left(\gamma_{i}-\bar{\gamma}\right) d x_{i}
$$

Aggregate gross output growth in (14) depends on technology shocks dt, plus returns to scale in the "typical" firm, $\bar{\gamma}$, multiplied by aggregate input growth. In addition, output growth depends on the realiocation $\bar{R}$, which contributes positively to growth if firms with high returns to scale have higher-thanaverage growth in inputs $d x_{i}$. Define the sectoral "cyclicality" parameter $\beta_{i}$ as the regression coefficient of $\mathrm{dx}$ on $\mathrm{dx} \mathrm{x}_{\mathrm{i}}$. The bias caused by the reallocation term (in the OLS regression) is then $\sum_{\mathrm{i}}\left(\gamma_{i}-\bar{\gamma}\right) \beta_{i}$. Hence, the bias is positive if $\gamma_{i}$ is positively correlated with $\beta_{i}$.

For value added, substitute into equation (11) from equation (8). With some rearranging, we can write aggregate value-added growth in a similar way, reflecting the direct contribution of inputs multiplied by "average" value-added returns to scale $\vec{\gamma}$; technology; and aggregation terms:

$$
d v=\bar{\gamma}^{v} \cdot d x^{v}+R^{v}+I+d t^{v} .
$$

$\mathrm{dt}^{\prime}{ }^{\prime}$ is the value-added weighted average of technology shocks $\mathrm{dt}_{i}{ }^{\mathrm{v}}$, and

${ }^{16}$ Aggregation can also fail because of factor rents or profit rates that differ across sectors. These effects are difficult to estimate, and existing empirical evidence on their importance is controversial. For simplicity, we thus abstract from these failures of aggregation here. However, we do consider factor rents theoretically in Section V. See Basu and Fernald (1995b) for a complete derivation. 


$$
\begin{gathered}
R^{V}=\sum_{i} w v_{i}\left(\gamma_{i}^{V}-\bar{\gamma}^{V}\right) \cdot d x_{i}^{V} \\
I=\sum_{i} w v_{i} \cdot\left(\gamma_{i}^{V}-1\right) \cdot\left(\frac{s_{M i}}{1-s_{M i}}\right) \cdot\left(d m_{i}-d y_{i}\right) .
\end{gathered}
$$

As with gross output, the value-added reallocation effect $R^{v}$ reflects the "covariance" between returns to scale and the cyclicality of input growth. I reflects variations in the intensity of intermediateinput use within firms that are imperfect competitors.

The aggregation equations (14) and (16) have several implications. First, aggregate demand instruments need not be uncorrelated with reallocation effects, and hence may be invalid. The problem is that demand shocks need not lead to equiproportionate changes in input use for all firms within the aggregate. For example, government defense spending may fall unequally on firms within the industry; some firms may be more sensitive than others to changes in oil prices.

Second, aggregation can plausibly explain the puzzles discussed in Section II. If heterogeneity is cyclical, then estimates at different levels of aggregation are likely to differ. Aggregation effects can in principle cause estimates to either rise or fall at different levels of aggregation. Hence, aggregation can explain the first puzzle, of higher estimates in aggregates than industries, as well as the second puzzle, of apparent diminishing returns in some industries. Finally, aggregation effects are likely to differ in gross output and value added, potentialily explaining why the two types of data yieid different results. ${ }^{17}$

Third, the parameters we estimate from aggregate data are not structural--they are complex combinations of structural parameters and behavioral responses to reallocation-inducing shocks. There need not be a stable relationship between inputs and outputs over different time periods or in response to different economic shocks. Hence, estimates may be sensitive to data and sample period.

Fourth, it now becomes unclear what parameter one wants for calibrating returns to scale. Authors calibrating one-sector models tend to focus on estimates of the average value-added returns to scale, $\vec{\gamma}^{v}$; if estimates differ at different levels of aggregation, this strategy may not be appropriate. We return to this point in Section V.

17 We can generate examples where gross-output data give better estimates of firm-level parameters than value-added data, and vice versa. Thus, there is no general proposition on this issue; it becomes an empirical matter which is preferred. 
We conclude by noting that it might seem strange that aggregation fails even under conditions where firm-level "productive" value added $V^{p}$ can be written as functions of two physically-homogeneous factors of production, capital and labor, and where these factors can move costlessly between firms. Under these assumptions, the theorems of Fisher (1993) would seem to assure the existence of an aggregate production function. Fisher's theorems do not apply in our setup, however, since factors are not necessarily allocated efficiently to maximize output. Since different firms may have different degrees of market power (corresponding to differences in degrees of returns to scale), the same factor has a different value of marginal product in different uses. Thus, reallocating a factor from one firm to another can change aggregate output.

\section{Aggregation Results}

This section explores the empirical importance of the aggregation effects identified in the previous section. At a minimum, the results suggest that these effects matter. Moreover,, these results plausibly yield more accurate estimates of firm-level parameters than those in Table 2.

We implement the decomposition in equations (14) and (16), using our sectoral estimates of returns to scale to calculate estimates of $R, R^{v}$, and $l$. We estimate "aggregation corrected" gross-output and value-added growth by subtracting these aggregation terms from actual growth in aggregate grossoutput and value-added. We then regress the result on aggregate inputs.

If aggregation effects operate only across industries, but not within industries, then aggregationadjusted estimates should provide unbiased estimates of the true average parameters. In this case, the estimates reported in this section should be close to those reported in Table 2 for the industry averages, differing only because of statistical estimation error. On the other hand, if industries themselves contain substantial aggregation effects, then the estimated aggregation corrections from industries to aggregates may also control for aggregation from firms to industries. Thus, we may obtain better estimates of firmlevel parameters from aggregate data than from partially-disaggregated data.

We return to the issue of interpretation after presenting results. We present only uninstrumented results, because in general the presence of aggregation effects implies that demand-side instruments are not valid. To check the empirical importance of this point, we regressed the estimated aggregation terms 
on each of our instruments. ${ }^{18}$ (Since the null hypothesis is that the instruments are valid, we calculated the gross-output and value-added terms using the instrumented industry estimates from Table 2, though the results are not much different if instead we use the uninstrumented estimates). For the change in the world price of oil, we can almost always reject the null. For the private economy as a whole, for example, the coefficient on the current oil price is significantly negative at the 0.001 level for both value added and gross output; the coefficient on the lagged change is significantly negative at the 0.01 level for valueadded and the 0.05 level for gross output. Government defence spending positively affects reallocations for manufacturing durables, but is otherwise insignificant, as is the political party of the president. These results thus verify the empirical importance of the theoretical point that the instruments we (and many others) use are not valid as instruments at an aggregate level. We have no reason to expect that the instruments are any more valid at an industry level.

In Table 3, we present aggregation-corrected aggregate results, using the uninstrumented industry estimates. We begin with two general observations. First, overall the estimates for the total private economy in column one suggest constant returns. Second, in all cases the implied values of $\gamma^{\mathrm{V}}$ in row two are very close to the direct value-added estimates in row three. This was not true in the results reported in Section II, and suggests that reallocation effects are an important explanation for the differences in results between gross output and value added.

Although the typical industry appears to have constant returns, manufacturing shows some evidence of increasing returns. This is particularly true in durables, where all of the estimates show statistically significant increasing returns. In nondurables, all of the estimates show slight decreasing retums, though they are not statistically different from one.

It is worth emphasizing that nowhere in Table 3 do we have the puzzle of statistically significant decreasing returns. Only in non-durables is there evidence of decreasing returns, and even there the results are not statistically different from one. We cannot say that the results are statistically different from those shown in Table 1, since the standard error in the uncorrected regression is very high; but it is worth noting that the standard error falls dramatically, since the fit of the regression improves substantially. These results are, however. statistically significantly different from those in Table 2.

\footnotetext{
18 Appendix III presents these regression results in detail.
} 
Overall. aggregation effects appear to be procyclical, leading to an economically substantial increase in estimates of returns to scale. Using value-added data is mainly a problem with non-durables; those results change substantially in an economically sensible way when we control for aggregation. For durables, corrections to value added make less of a difference. This suggests that the value-added reallocation terms are particularly important for non-durables, and relatively unimportant for durables.

The results in Table 3 show that correcting for aggregation does not recover industry-level averages from aggregate data. Can we nevertheless interpret the results in Table 3 as reliable estimates of the average firm-level parameters in the economy? Without detailed firm-level data we cannot be certain, but can suggest the factors that matter. Suppose equation (14) for gross output applies for aggregation over firms to the level of an individual industry $\mathrm{i}$. We then aggregate over industries to the level of the entire economy. Omitting the technology term, this gives:

$$
d y=\bar{\gamma} d x+\sum_{i} w_{i} R_{i}+R
$$

The unobserved within-industry reallocation terms $R_{i}$ are plausibly correlated with both sectoral and aggregate input growth. For example, idiosyncratic shocks to $\mathrm{dx}_{\mathrm{i}}$ may reflect procyclical entry by lowproductivity firms, and hence lower estimates of returns to scale; systemic shocks to dx may change factor prices and lead low-productivity firms to exit, and hence raise estimates. In addition, aggregate shocks likely reflect aggregate income changes, leading more-durable producers (even within a two-digit category) to increase their inputs relatively more. Thus, industry-level reallocations associated with idiosyncratic and systematic shocks need not have the same sign. Suppose the $R_{i}$ are related in a (relatively) structural way to $d x_{i}$ and $d x:^{19}$

$$
R_{i}=\delta_{i} d x_{i}+\eta_{i} d x .
$$

Let $\sigma_{i}$ equal $\operatorname{cov}\left(d x_{i}, d x\right) / v a r\left(d x_{i}\right)$, the regression coefficient of $d x$ on $d x_{i}$. Then the average estimate over industries, $\bar{\gamma}$, equals $\bar{\gamma}+\bar{\delta}+\bar{\sigma} \bar{\eta}$. Substituting $\hat{\gamma}_{1}$ and $\bar{\gamma}$ into equation (15) for $\mathbf{R}$ gives $\hat{R}$. With some rearranging of equation (14), aggregation-corrected growth in aggregate output equals:

19 In practice, the $R_{i}$ need not be structural. For the heuristic argument that follows, this point is unimportant. For the same heuristic reason, we omit disturbance terms, which would add statistical error to the equations that follow without changing any of the substance. 


$$
d y-\hat{R}=(\bar{\gamma}+\bar{\delta}+\bar{\eta}) d x-\sum_{i} w_{i}\left(\sigma_{i} \eta_{i}=\bar{\sigma} \eta\right) \cdot\left(d x_{i}-d x\right)
$$

When we estimate equation (20), various results are possible, depending on the signs and magnitudes of the parameters. As one case, suppose the $\eta_{i}$ equal zero. Then equation (20) estimates $\bar{\gamma}+\bar{\delta}$. These are same quantities estimated in Table 2 , with the same biases. In this case, our aggregation-corrected estimates should recover Table 2.

As a second case, though, suppose that $\bar{\delta}$ and $\bar{\eta}$ are equal in magnitude and opposite in sign, and that the $\sigma_{i}$ are close to zero. In this case, the aggregate estimate from equation (20) correctly estimates $\bar{\gamma}$, without bias. Then estimated $\hat{\mathrm{R}}$ correctly controis not just for aggregation from industries to aggregates, but for aggregation from firms to industries. Thus, the estimates in Table 3 provide the correct weighted average of firm-level returns to scale, while the estimates in Table 2 (though relying only on disaggregated data) do not.

In our data, we cannot be entirely sure which case is closer to the truth, since we do not observe the $\mathbf{R}_{i}$. Nevertheless, our priors are that case two is closer to the truth, and hence that aggregationcorrected estimates provide better estimates of the average firm parameters. First, Table 2 suggests that $\bar{\delta}$ is negative, with a magnitude of at least -0.17 (given a point estimate of 0.83 and a minimum on economic grounds of 1.00 ). Second, results in this section suggest that the aggregate reallocation term $\mathrm{R}$ is procyclical; if the reallocation response to aggregate shocks is similar within as across industries, then $\bar{\eta}$ is positive. Third, the weighted average $\bar{\sigma}$ in our data is 0.3 ; while not zero, it is nonetheless considerably below unity. Finally, the estimated $\sigma_{i}$ have little correlation with the sectoral cyclicality of inputs $\beta_{i}$, so that the bias from the omitted final term in equation $(20)$ is probably small. ${ }^{20}$

The results in this section thus suggest that the average firm appears to have approximately constant returns to scale, and suggests that aggregation effects can explain the three puzzles presented in Section III. Nevertheless, reallocation produces the same changes in average productivity as if there were

20 It is, of course, surprising that $\sigma_{i}$ and $\beta_{i}$ have such a small correlation, given that $\sigma_{i}=\beta_{i} \operatorname{var}(\mathrm{dx}) / \operatorname{var}\left(\mathrm{d} x_{i}\right)$. In the data, high $\beta_{i}$ industries, such as autos, tend to be high $\operatorname{var}\left(\mathrm{dx} \mathrm{x}_{i}\right)$ industries. To get a sense for the magnitude of the potential bias, assume that the unobserved $\eta_{i}$ are identical across sectors. The bias in estimating returns to scale caused by the final term is then $-\bar{\eta} \Sigma w_{i}\left(\sigma_{i}-\bar{\sigma}\right) \beta_{i}$, which in the data equals $-\vec{\eta}^{*}(0.05)$. Even if $\eta$ is large $(0.5$, say), the bias is small. 
a representative firm with increasing returns. So the economic question remains: Which estimate more accurately captures the economic forces at work in business cycles? The next section explores this question.

\section{Implications for Calibrating Macro Models}

When can we ignore heterogeneity in production and act as if a representative firm produces all output? Doing so means modeling the production side of the economy using an aggregate production function for GDP. In this section we first ask, is this procedure ever sensible if the world actually has significant heterogeneity? We then ask, what parameters should one use to calibrate the assumed aggregate production function? In particular, can one use estimates that use aggregate data and ignore heterogeneity?

We address these questions using a very simple, stylized example. In one case, it is safe to ignore heterogeneity: we can model a multi-sector world as if there were only one sector and calibrate it using only aggregate data, as one would calibrate a one-sector model. But in another case, this procedure is misleading. Interestingly, the appropriate procedure depends on non-production institutions in the economy. Thus, our example shows that there are no general answers to the questions we posed: the answers depend on the precise model.

Our example modifies Basu (1995b). The world is static. There is a continuum of consumers, indexed by $i \in[0,1]$. Each maximizes expected utility from consumption $c$ and leisure $x$, subject to a standard budget constraint:

$$
\operatorname{Max} E(U)=E(\alpha c+v(x)) \text { s.t. } c \leq \pi+w(\bar{l}-x)
$$

where $\bar{l}$ is an individual's endowment of time, $\pi$ is profit, and $w$ is the real wage. We often work with labor supply: $l=\bar{l}-\mathrm{x}$. We assume $\mathrm{v}^{\prime}>0, \mathrm{v}^{\prime \prime}<0, \mathrm{v}^{\prime}(\bar{l})<\alpha$ and $\mathrm{v}^{\prime}(0)>\alpha$.

Initially, suppose the production side of the economy consists of a single firm that employs all workers. Aggregate labor is defined as $\int_{0}^{1} l_{i} d i$, and the firm's production function is

$$
Y=A L^{r} \text {. }
$$

where $\gamma \geq 1$. If $\gamma>1$, then the firm must price with a markup above marginal cost to cover its costs. 
Although only one firm produces at any given time, we assume that there are a large number of potential entrants who can enter costlessly and capture any economic profits. Thus the incumbent sets its price to make exactly zero profits, so from equation (3), the firm's markup $\mu$ equals returns to scale $\gamma$. The real wage in this economy is thus $\frac{\gamma}{\mu} A L^{\gamma-1}=A L^{\gamma-1}$.

Equilibria of this economy are symmetric, so $\mathrm{L}=l$. So far there is no uncertainty in the economy, and in equilibrium the first-order condition for utility maximization is:

$$
v^{\prime}(\bar{l}-L)=\alpha A L^{\gamma-1} .
$$

Following Cooper and John (1988), this economy necessarily displays multiple, symmetric, Pareto-ranked equilibria if, for some $L^{*}$ that solves equation (23) above, we have

$$
\frac{d \ln v^{\prime}}{d \ln l}<\left.\frac{d \ln w^{\prime}}{d \ln l}\right|_{d l=d l}=\gamma-1 \text {. }
$$

Clearly, for (24) to hold, $\gamma$ must be sufficiently larger than 1: Increasing returns of a strong form (diminishing margina! cost) lead to an upward-sloping labor demand curve, and hence make the real wage rise with aggregate labor supply. If this effect is sufficiently strong, the increase in the wage more than offsets the disutility of supplying additional labor. Given the assumptions about $v$ above, we shall then have an odd number of locally-unique equilibria, with higher-L equilibria Pareto-preferred. In this economy, therefore, the critical parameter that determines whether there are multiple equilibria is the degree of returns to scale of the representative firm, which can be estimated using aggregate data. ${ }^{21}$

\section{B. An Economy with Heterogeneity}

We now consider two examples in which the production side of the economy consists of two firms, each producing with constant returns to scale. However, one of the firms has a higher level of

\footnotetext{
${ }^{21}$ As we noted above, the increasing returns need to take the form of dimininishing marginal cost. This is a robust feature of models where there are increasing returns to agglomeration with a constant markup (e.g. Farmer and Guo 1994). Of course, as equation (3) shows, increasing returns to scale just means that average cost exceeds marginal cost, and is compatible with any slope of the marginal cost curve. One can calibrate the slope of the marginal cost curve from estimates of the degree of returns to scale only by assuming that there are no fixed costs.
} 
productivity than the other. Thus, $Y_{i}=A_{i} L_{i}$, where we assume $A_{1}>A_{2}$.

Both firms are competitive and price at marginal cost. However, unions in firm 1 succeed in extracting all the benefits of higher productivity in the form of higher wages, so both firms have equal unit costs (and equal prices). Hours in the high-productivity firm are rationed. Thus, the wage in firm 1 is $w_{1}=A_{1}$, and the wage in firm 2 is $w_{2}=A_{2}$. The rationing rule takes the form of having a share, $s$, of aggregate labor hours devoted to work in firm 1 , with the remainder going to firm $2: \mathrm{L}_{1}=\mathrm{sL}$, and $L_{2}=(l-s) L$. Thus, the average wage, $\bar{w}$, is $s A_{1}+(1-s) A_{2}$. Finally, we let $s$ depend on aggregate output: $s=s(Y)$. For reasons we do not model, we assume $s^{\prime}(Y)>0$.

Now suppose we estimate "returns to scale" by estimating equation (2) or (6) using aggregate data from this economy. As in Basu (1995b), we find

$$
\dot{\gamma} \equiv \frac{d \ln Y}{d \ln L}=\left[1-s \varepsilon_{s} \frac{A_{1}-A_{2}}{s A_{1}+(1-s) A_{2}}\right]^{-1} \text {, where } \varepsilon_{s} \equiv \frac{d s}{d Y} \frac{Y}{s}
$$

Since $\varepsilon_{s}$ is positive, $\hat{\gamma}>1$. Let us suppose that $\varepsilon_{s}, A_{1}$, and $A_{2}$ are chosen so that $\hat{\gamma}$ equals the representative firm's $\gamma$ in equation (22). Does this parameter play the same role here as it does in the single-firm economy, where (for given $v$ ) it determines whether the economy has multiple equilibria? ${ }^{22}$

\section{Egalitarian rationing}

Suppose we first consider one institution of labor supply, which we might term "egalitarian rationing." Under this scheme, each worker is allowed to work a fixed number of hours. $\mathrm{H}$, in firm $\mathrm{I}$ and then is free to work as many hours as he wishes in firm 2. In equilibrium, $H=s(Y) l=s(Y) L$. So an individual worker's budget constraint becomes $c \leq \pi+w_{1} H+w_{2}(\bar{l}-\mathrm{H}-\mathrm{x})$.

Note that at the margin (as long as $\mathrm{H}$ is not too large), the wage is always the low wage, $\mathrm{w}_{2}$.

\footnotetext{
22 In this example the failure of an aggregate production function comes from imperfect competition in the labor market. We assumed away this source in Section IIl for simplicity, as well as because we have no way to assess its importance in our data. Katz and Summers (1989) argue there is empirica! evidence in favor of significant labor rents of the sort assumed in this example, but Topel (1989) criticizes their assumptions. This argument does not concern us, however, since our simple, static example is not meant to describe the world, but simply provides a convenient example to establish that certain results are possible.
} 
Small changes in $\mathrm{Y}$ (and hence $s(\mathrm{Y})$ and $\mathrm{H}$ ) do not change this property. From the point of view of the worker, the change in the average wage is inframarginal, and is not reflected in a change in the marginal compensation for labor. Then we can see that equation (24) is not satisfied, and this economy has a unique equilibrium. Thus, although this economy has procyclical labor productivity (and procyclical labor compensation per hour) to exactly the same degree as our one-firm economy, it does not have multiple equilibria. In this case, assuming a representative firm and calibrating it with the parameter estimated from aggregate data does not accurately describe the economics at work.

\section{Rationing by lottery}

Now suppose that instead of rationing high-paid hours evenly among workers, the opportunity to work at the high-wage firm is allocated by lottery. Each worker enters the lottery and specifies in advance the number of hours he is willing to work, regardless of the firm at which he is employed. Thus, workers

make their labor supply decisions without knowing their individual ex post real wages. They do know, however, the probability distribution of wages.

Since the problem is now one of individual (though not aggregate) uncertainty, the first-order condition becomes:

$$
v^{\prime}(\bar{l}-i)=\alpha E(w)=\alpha\left(s(Y) A_{1}+(1-s(Y)) A_{2}\right) .
$$

The condition for multiple equilibria thus is

$$
\begin{aligned}
\frac{d \ln v^{\prime}}{d \ln l}<\frac{d \ln w^{\prime}}{d \ln l} & =\frac{A_{1}-A_{2}}{s A_{1}+(1-s) A_{2}} s \varepsilon_{s} \frac{d \ln Y}{d \ln L} \\
& =\hat{\gamma}-1 .
\end{aligned}
$$

Equation (27) shows that in this case the two-sector economy with heterogeneity has multiple equilibria under just the same condition as the one-sector economy: if the $\hat{\gamma}$ estimated from aggregate data is above the same critical value in both cases.

\section{Implications}

This example shows that one cannot draw general lessons about calibrating one-sector models from aggregate data in the presence of significant heterogeneity. Nevertheless, several features of the example 
seem to have general implications.

First, we note that if any single summary statistic is useful, it is likely to be the degree of returns to scale estimated from aggregate data without composition corrections. In all of the cases we examined, this parameter correctly captures the procyclical behavior of average labor productivity and average labor compensation (under the assumption that the $s(\mathrm{Y})$ function is structural). A one-sector model calibrated with the average $\gamma$ (always 1 in the multi-firm economy), would be unabie to replicate this behavior.

Second, this example shows that the aggregate parameter also can fail to capture the relevant economics in the multi-firm economy, although it always does so in the single-firm economy. The reason is that in the multi-firm economy, the procyclicality of aggregate productivity always reflects the procyclical "average marginal product" of labor, but only under some circumstances does that translate to a procyclical "marginal marginal product" of labor. However, it is the latter that is relevant for economic decisions (in this case, labor supply). Thus, the lesson may be that it is safer to ignore reallocation if the institutions being modeled are such that average and marginal factor prices move more or less together. However, it is difficult to say when this would occur, since there is no completely-accepted theory of imperfect competition that explains how the same input can have different marginal products in different uses.

\section{Conclusions}

On both empirical and theoretical grounds, heterogeneity in production appears important for macroeconomics. Although estimates of returns to scale vary widely across relatively disaggregated industries, the average industry appears to produce with constant or even decreasing retums. Taken literally, apparent widespread decreasing returns contradicts empirical evidence of small economic profits. These industry results also contrast sharply with aggregate results at the level of manufacturing or the private business economy, which show large increasing returns. A representative-firm framework, used in many recent macro models, cannot easily explain these findings. Another popular explanation for procyclical productivity, unobserved changes in factor utilization, also cannot explain these findings, since variable utilization explains apparent industry increasing returns rather than apparent decreasing returns.

An explanation for these findings is that neither industries nor aggregates behave like firms. In 
particular. aggregating across imperfectly-competitive producers can explain the puzzles we identify, since similar factors employed in different industries can then have different marginal products. For example, durable-goods industries appear to have larger returns to scale than the average industry. The output of durable-goods industries is also more procyclical than the average. Thus, the additional factors employed in a boom have marginal products that are higher than the average products of factors in use, leading aggregate productivity to be procyclical.

If long-run returns to scale cannot be lower than one. this story in its pure form requires that some industries have increasing returns." However, aggregation can exaggerate a modest degree of increasing returns, and an econometrician might misinterpret this as evidence for large increasing returns at a representative firm. On the other hand, reallocation effects can in principle work in the opposite direction, making productivity countercyclical in some industries and thus explaining the puzzle of apparent industry diminishing returns. Hence, aggregation issues can explain differences in results at different levels of aggregation, in different types of data, and over different sample periods.

We correct for economy-wide reallocation to the extent feasible with the available data. These results suggest that aggregation effects are important in the data. They also suggest that a typical firm produces with approximately constant returns to scale, although we cannot reject a modest degree of increasing returns. These results are consistent with those from plant-level studies, such as Baily, Hulten, and Campbell (1992).

Many macroeconomic issues depend on the production parameters within the economy. However, the relevant parameter may not be the weighted average of returns to scale over all firms in the economy. Cyclical reallocations are not simply a bias in estimating returns to scale; they cause real output to vary, and may themselves serve as important macroeconomic mechanisms. We illustrate this theoretical possibility in a simple model with multiple heterogeneous firms, each producing with constant returns to scale. This economy can display multiple Pareto-ranked equilibria-a result requiring large increasing returns if production took place at a single firm. Furthermore, the critical parameter is the degree of returns to scale that an econometrician would estimate using aggregate data without correcting for

23. As our example of Section V shows, this need not be true if there is imperfect competition in factor markets. 
reallocations.

This multi-firm economy does not always exhibit multiple equilibria. however, and whether it does so depends on non-production features of the economy. Thus, to investigate many recent hypotheses in macroeconomics, one may need to construct multi-sector dynamic general-equilibrium models with imperfect competition and heterogeneity, and confront the aggregation issues from first principles. Until then, the fact that the world seems best described by approximately constant returns at the firm level does not necessarily allow us to reject macroeconomic parables in which increasing returns at a representative firm play a central role in explaining economic fluctuations. Ascertaining which paradigm provides better macroeconomic insights is an important task for future research. 


\section{BIBLIOGRAPHY}

Baily, Martin. Charles Hulten. and David Campbell. "Productivity Dynamics in Manufacturing Plants." Brookings Papers Econ. Activity (Microeconomics), no. 1 (1992): 187-267.

Bartelsman. Eric J. "Of Empty Boxes: Retums to Scale Revisited." Econ. Letters 49 (July 1995) 59-67.

Basu, Susanto. "Intermediate Goods and Business Cycles: Implications for Productivity and Welfare." A.E.R. 85 (June 1995): 512-31 (a).

"Comment." In NBER Macroeconomics Annual, vol. 10, edited by Ben Bernanke and Julio Rotemberg. Cambridge, Mass: MIT Press. 1995 (b). 1995 (c) .

"Procyclical Productivity: Increasing Returns or Cyclical Utilization?" Forthcoming, Q.J.E.,

Basu. Susanto, and Fernald, John G. "Are Apparent Productive Spillovers a Figment of Specification Error?" J. Monetary Econ. 36 (August 1995): 165-188 (a).

and _ . Aggregate Productivity and the Productivity of Aggregates." Working paper no. 5382. Cambridge, Mass.: NBER. November 1995 (b).

Beaudry. Paul. and Devereux, Michael. "Monopolistic Competition, Price Setting and the Effects of Real and Monetary Shocks." Manuscript. Vancouver: Univ. British Columbia, 1994.

Benhabib. Jess, and Farmer, Roger E. A. "Indeterminacy and Sector-Specific Externalities." Manuscript. New York: New York Univ.. October 1995.

Bils. Mark and Jang-Ok Cho. "Cyclical factor utilization." J.M.E. 33 (1994): 319-354.

Bruno, Michael. "Raw Materials, Profits, and the Productivity Slowdown." Q.J.E. 109 (February 1984): $1-30$.

Burnside. Craig. "What Do Production Function Regressions Tell Us About Increasing Returns to Scale and Externalities?" Manuscript. Washington: The World Bank, November 1995.

. Martin Eichenbaum, and Sergio Rebeio. "Capital Ütilization and Returns to Scale." in NBER Macroeconomics Annual, vol. 10, edited by Ben Bernanke and Julio Rotemberg. Cambridge. Mass.: MIT Press, 1995.

Caballero. Ricardo and Lyons, Richard. "External Effects in U.S. Procyclical Productivity." J. Monetary Econ. 29 (April 1992): 209-26.

Domar. Evsey. "On the Measurement of Technological Change." Econ. J. 71 (1961): 709-729.

Domowitz. Ian: Hubbard, R. Glenn: and Petersen, Bruce C. "Market Structure and Cyclical Fluctuations in U.S. Manufacturing." Rev. Econ. and Statis. 70 (February 1988): 55-66. 
Farmer, Roger and Guo. Jang-Ting. "Real Business Cycles and the Animal Spirits Hypothesis." J. Econ. Theory 63 (June 1994): 42-72.

Fisher, Franklin M. Aggregation. Cambridge, Mass.: MIT Press, 1993.

Griliches, Zvi and V. Ringstad. Economies of Scale and the Form of the Production Function. Amsterdam: North-Holland, 1971.

Hall, Robert E. "The Relation between Price and Marginal Cost in U.S. Industry." J.P.E. 96 (October 1988): $921-47$.

. "Invariance properties of Solow's Productivity Residual." In Growth/Productivity/Linemployment. edited by Peter Diamond. Cambridge, Mass.: MIT Press, 1990.

Hall, Robert E., and Jorgenson. Dale. "Tax Policy and Investment Behavior." A.E.R. 57 (June 1967): $391-414$.

Jorgenson, Dale; Gollop. Frank: and Fraumeni, Barbara. Productivity and U.S. Economic Growth. Cambridge, Mass.: Harvard University Press, 1987.

Katz, Lawrence F. and Lawrence H. Summers. "Industry Rents: Evidence and Implications." Brookings Papers Econ. Activin (Microeconomics), no. 1 (1989): 209-290.

Nelson. Charles, and Startz, Richard. "Some Further Results on the Exact Small Sample Properties of the Instrumental Variables Estimator." Econometrica 58 (1990): 967-976.

Norrbin, Stefan C. "The Relation between Price and Marginal Cost in U.S. Industry: A Contradiction." J.P.E. 101 (December 1993): 1149-1166.

Perli, Roberto. "Indeterminacy, Home Production, and the Business Cycle: A Calibrated Analysis." Manuscript. New York: New York Univ., April 1995.

Rotemberg, Julio. and Woodford. Michael. "Oligopolistic Pricing and the Effects of Aggregate Demand on Economic Activity:" J.P.E. 100 (December 1992): 1153-1207.

and _ . Imperfect Competition and the Effects of Energy Price Increases on Economic Activity." Manuscript. Cambridge, Mass.: MIT, 1993.

and _ Dynamic General Equilibrium Models with Imperfectly Competitive Product Markets." In Frontiers of Business Cycle Research, edited by Thomas F. Cooley. Princeton, N.J.: Princeton Univ. Press. 1995.

Schmitt-Grohé, Stephanie. "Comparing Four Models of Fluctuations Due to Self-Fulfilling Expectations." Manuscript. Washington. D.C.: Board of Governors of the Federal Reserve System, 1995.

Staiger, Douglas, and Stock, James. "Instrumental Variables Regression with Weak Instruments." Technical Working Paper no. 151. Cambridge, Mass.: NBER, January 1994.

Topel. Robert H. "Comment." Brookings Papers Econ. Activity (Microeconomics), no. I (1989). 
Table 1

Âggregate Estimates

\begin{tabular}{||c|c|c|c|c||}
\cline { 2 - 5 } \multicolumn{1}{c|}{} & $\begin{array}{c}\text { Private } \\
\text { Economy }\end{array}$ & $\begin{array}{c}\text { Manufact } \\
\text { uring }\end{array}$ & $\begin{array}{c}\text { Manufact. } \\
\text { Durables }\end{array}$ & $\begin{array}{c}\text { Manufact. } \\
\text { Non- } \\
\text { Durables }\end{array}$ \\
\hline PARAMETER & \multicolumn{4}{|c||}{ Two-Stage Least Squares } \\
\hline $\begin{array}{c}\text { Gross Output } \\
\gamma\end{array}$ & $\begin{array}{c}1.27 \\
(0.10)\end{array}$ & $\begin{array}{c}1.09 \\
(0.07)\end{array}$ & $\begin{array}{c}1.14 \\
(0.05)\end{array}$ & $\begin{array}{c}0.86 \\
(0.15)\end{array}$ \\
\hline $\begin{array}{c}\text { Implied Value- } \\
\text { Added } \gamma^{\prime}\end{array}$ & $\begin{array}{c}1.72 \\
(0.36)\end{array}$ & $\begin{array}{c}1.29 \\
(0.29)\end{array}$ & $\begin{array}{c}1.46 \\
(0.21)\end{array}$ & $\begin{array}{c}0.66 \\
(0.28)\end{array}$ \\
\hline $\begin{array}{c}\text { Direct Value- } \\
\text { Added }\end{array}$ & $\begin{array}{c}1.46 \\
\text { Estimate }\end{array}$ & $\begin{array}{c}1.10 \\
(0.38)\end{array}$ & $\begin{array}{c}1.40 \\
(0.33)\end{array}$ & $\begin{array}{c}0.04 \\
(0.27)\end{array}$ \\
\hline
\end{tabular}

\begin{tabular}{||c|c|c|c|c||}
\cline { 2 - 5 } \multicolumn{1}{c|}{} & \multicolumn{4}{c||}{ Ordinary Least Squares } \\
\hline $\begin{array}{c}\text { Gross Outpuit } \\
\gamma\end{array}$ & $\begin{array}{c}1.23 \\
(\mathbf{0 . 0 6 )}\end{array}$ & $\begin{array}{c}1.12 \\
(\mathbf{0 . 0 4 )}\end{array}$ & $\begin{array}{c}1.13 \\
(0.03)\end{array}$ & $\begin{array}{c}0.99 \\
(0.10)\end{array}$ \\
\hline $\begin{array}{c}\text { Implied Value- } \\
\text { Added } \gamma^{\prime}\end{array}$ & $\begin{array}{c}1.57 \\
(0.20)\end{array}$ & $\begin{array}{c}1.41 \\
(0.20)\end{array}$ & $\begin{array}{c}1.40 \\
(0.12)\end{array}$ & $\begin{array}{c}0.97 \\
(0.31)\end{array}$ \\
\hline $\begin{array}{c}\text { Direct Value- } \\
\text { Added } \\
\text { Estimate }\end{array}$ & $\begin{array}{c}1.29 \\
(0.23)\end{array}$ & $\begin{array}{c}1.21 \\
(0.19)\end{array}$ & $\begin{array}{c}1.32 \\
(0.14)\end{array}$ & $\begin{array}{c}0.52 \\
(0.44)\end{array}$ \\
\hline
\end{tabular}

Sample Period is 1959-89. In both panels, the first row presents single-equation estimates of equation (2) which are converted in the second row using equation (10). The third row estimates equation (5). Instruments are the price of oil, government defense spending, and the political party of the president, with one lag of each. 
Table 2

Weighted Average of Sectoral Estimates

\begin{tabular}{|c|c|c|c|c||}
\cline { 2 - 5 } \multicolumn{1}{c|}{} & $\begin{array}{c}\text { Private } \\
\text { Economy }\end{array}$ & $\begin{array}{c}\text { Manufact } \\
\text { uring }\end{array}$ & $\begin{array}{c}\text { Manufact. } \\
\text { Durables }\end{array}$ & $\begin{array}{c}\text { Manufact. } \\
\text { Non- } \\
\text { Durables }\end{array}$ \\
\hline PARAMETER & \multicolumn{4}{|c|}{ Two-Stage Least Squares } \\
\hline $\begin{array}{c}\text { Gross Output } \\
\gamma\end{array}$ & $\begin{array}{c}0.97 \\
(0.12)\end{array}$ & $\begin{array}{c}0.92 \\
(0.05)\end{array}$ & $\begin{array}{c}1.08 \\
(0.03)\end{array}$ & $\begin{array}{c}0.73 \\
(0.11)\end{array}$ \\
\hline $\begin{array}{c}\text { Implied Value- } \\
\text { Added } \gamma^{\prime}\end{array}$ & $\begin{array}{c}1.16 \\
(0.23)\end{array}$ & $\begin{array}{c}1.06 \\
(0.08)\end{array}$ & $\begin{array}{c}1.32 \\
(0.12)\end{array}$ & $\begin{array}{c}0.67 \\
(0.12)\end{array}$ \\
\hline $\begin{array}{c}\text { Direct Value- } \\
\text { Added }\end{array}$ & $\begin{array}{c}0.94 \\
(0.22)\end{array}$ & $\begin{array}{c}0.87 \\
(0.15)\end{array}$ & $\begin{array}{c}1.26 \\
(0.16)\end{array}$ & $\begin{array}{c}0.26 \\
(0.29)\end{array}$ \\
\hline Estimate & & & & \\
\hline
\end{tabular}

\begin{tabular}{|c|c|c|c|c||}
\cline { 2 - 5 } \multicolumn{1}{c|}{} & \multicolumn{4}{|c|}{ Ordinary Least Squares } \\
\hline $\begin{array}{c}\text { Gross Output } \\
\gamma\end{array}$ & $\begin{array}{c}0.83 \\
(0.04)\end{array}$ & $\begin{array}{c}0.93 \\
(0.03)\end{array}$ & $\begin{array}{c}1.07 \\
(0.02)\end{array}$ & $\begin{array}{c}0.77 \\
(0.05)\end{array}$ \\
\hline $\begin{array}{c}\text { Implied Value- } \\
\text { Added } \gamma^{v}\end{array}$ & $\begin{array}{c}0.89 \\
(0.07)\end{array}$ & $\begin{array}{c}1.03 \\
(0.05)\end{array}$ & $\begin{array}{c}1.28 \\
(0.06)\end{array}$ & $\begin{array}{c}0.66 \\
(0.06)\end{array}$ \\
\hline $\begin{array}{c}\text { Direct Vaiue- } \\
\text { Added } \\
\text { Estimate }\end{array}$ & $\begin{array}{c}0.54 \\
(0.09)\end{array}$ & $\begin{array}{c}0.66 \\
(0.08)\end{array}$ & $\begin{array}{c}1.07 \\
(0.07)\end{array}$ & $\begin{array}{c}0.06 \\
(0.15)\end{array}$ \\
\hline
\end{tabular}

Sample Period is 1959-89. In both panels, the first row presents gross-output-weighted averages of singleequation industry estimates of equation (2). The second row converts each industry estimate using equation (10), then averages with value-added weights. The third row presents value-added estimates of equation (5). Instruments are the price of oil, government defense spending, and the political party of the president, with one lag of each. 
Table 3

Aggregate Estimates

Corrected for Reallocations

\begin{tabular}{||c|c|c|c|c||}
\cline { 2 - 5 } \multicolumn{1}{c|}{} & $\begin{array}{c}\text { Private } \\
\text { Economy }\end{array}$ & $\begin{array}{c}\text { Manufact } \\
\text { uring }\end{array}$ & $\begin{array}{c}\text { Manufact. } \\
\text { Durables }\end{array}$ & $\begin{array}{c}\text { Manufact. } \\
\text { Non- } \\
\text { Durables }\end{array}$ \\
\hline $\begin{array}{c}\text { Gross Output } \\
\gamma\end{array}$ & $\begin{array}{c}1.01 \\
(0.05)\end{array}$ & $\begin{array}{c}1.08 \\
(0.04)\end{array}$ & $\begin{array}{c}1.11 \\
(0.03)\end{array}$ & $\begin{array}{c}0.96 \\
(0.08)\end{array}$ \\
\hline $\begin{array}{c}\text { Impiied Vaiue- } \\
\text { Added } \gamma^{\prime}\end{array}$ & 1.02 & 1.26 & 1.33 & 0.87 \\
\hline $\begin{array}{c}\text { Direct Value- } \\
\text { Added }\end{array}$ & 1.03 & $(0.16)$ & $(0.11)$ & $(0.23)$ \\
Estimate & $(0.18)$ & $(0.18)$ & $(0.15)$ & $(0.27)$ \\
\hline
\end{tabular}

Sample Period is 1959-89. Estimated aggregation terms are subtracted from gross output growth and value added growth before OLS regressions on input growth. For further description. see text. 


\section{Appendix I \\ Detailed Derivations of Equations in Section I}

This appendix derives the equations in the Section I of the paper in detail. We begin with the following production function for a firm:

$$
Y=F(K, L, M, T)
$$

$Y$ is gross output. $K$ and $L$ are primary inputs of capital and labor, while $M$ is intermediate inputs of energy and materials. $T$ is an index of the state of technology. We assume that the production function is homogeneous of degree $\gamma$ in capital, labor, and intermediate goods.

Differentiating the production function (Al), we can express the growth rate of output, dy, as:

$$
d y=\left(\frac{F_{K} K}{Y}\right) d k+\left(\frac{F_{L} L}{Y}\right) d l+\left(\frac{F_{M} M}{Y}\right) d m+d t .
$$

Lower-case letters represent logs of their upper-case counterparts, so all of the quantity variables in (A2) are $\log$ differences, or growth rates. $F$, represents the derivative of $F$ with respect to argument $J$. For convenience. we normalize to unity the elasticity of output with respect to technology $T$. Equation (A2) says that output growth depends on technology shocks plus a weighted sum of input growth. where the weights depend on the output elasticities.

The sum of the output elasticities equals the degree of returns to scale $\gamma$, so that

$$
\gamma=\left(\frac{F_{K} K}{Y}\right)+\left(\frac{F_{L} L}{Y}\right)+\left(\frac{F_{M} M}{Y}\right)
$$

Suppose that firms have some degree of monopoly power in the goods markets but are price takers in factor markets. The first-order conditions for cost minimization then imply: 


$$
\begin{gathered}
\mathrm{A} 2 \\
P_{J}=\lambda F_{J}, J=K, L, M,
\end{gathered}
$$

where $\lambda$ is a Lagrange multiplier with the interpretation of marginal cost, and $P$, is the shadow value of the Jth input as perceived by the firm. (As discussed below, this shadow value may or may not be observable as the input price.) By definition. the markup $\mu$ of the output price over marginal cost is $P / \lambda$. Hence. we can rewrite the above equation as:

$$
\begin{aligned}
{\left[\frac{F_{J}}{Y}\right] } & =\left(\frac{P_{J}}{\lambda}\right)\left(\frac{J}{Y}\right)=\left(\frac{P_{J}}{M C}\right)\left(\frac{J}{Y}\right) \\
& =\left(\frac{P}{M C}\right)\left(\frac{P_{J}}{P Y}\right) \\
& =\mu\left(\frac{P J}{P Y}\right] \equiv H s_{J}, \quad J=K, L, M .
\end{aligned}
$$

Thus. the elasticity of output with respect to any factor $J$ equals a markup $\mu$ multiplied by the share of that input in total revenue, $s_{\jmath}$. Note that the price of capital, $P_{k}$, must be defined as the rental cost of capital. It does not include possible profits, which generally are also payments to capital. With perfect competition, where $\mu=1$. equation (A5) just states that the elasticity of output with respect to any input equals the input's share in revenue. Under imperfect competition, the elasticity of output exceeds the revenue share.

Using the first line of equation (A5), we can rewrite equation (A3) as

$$
\gamma=\frac{1}{M C}\left(\frac{\sum_{J} P_{J}}{Y}\right)=\frac{A C}{M C} .
$$

Thus, cost minimization implies that returns to scale $y$ equals the ratio of average to marginal cost. Increasing returns can take different forms. e.g., no fixed costs but diminishing marginal cost: or fixed costs with flat or upward sloping marginal cost. Under cost minimization, we can use equation (A6) to write an identity linking returns to scale and the markup: 


$$
\gamma=\frac{A C}{M C}=\left(\frac{P}{M C}\right)\left(\frac{A C}{P}\right)=\mu\left(1-s_{\pi}\right)
$$

where $s_{z}$ is the share of profits in total revenue. Equation (A7) then implies that the output elasticities, which equal $\mu s_{j}$. also equal $\gamma c_{\jmath}$, where $c_{\jmath}$ is the share of payments to input $J$ in total costs. Hence, we can write the total differential of output as:

$$
\begin{aligned}
d y & =\gamma \cdot\left[c_{L} d l+c_{K} d k+\left(1-c_{L}-c_{K}\right) d m\right]+d t \\
& \equiv \gamma \cdot d x+d t .
\end{aligned}
$$

$d x$ is a cost-weighted sum of the growth rates of the various inputs. We weight factors by their cost shares rather than revenue shares. since as Hall (1988) shows, with markup pricing the measured Solow residual is procyclical, even with constant returns and no change in technology. Note that nothing in the above derivation relies on profit maximization: it depends solely on the production function and cost minimization.

Suppose that all factors are freely variable, so that there are no quasi-fixed factors. Then we can observe $P_{L}$ and $P_{M}$ as the market prices of $L$ and $M$, and construct $P_{K}$ as the steady-state rental rate of capital following Hall and Jorgenson (1967) and Hall (1990), allowing us to create the cost shares. If, however. capital is quasi-fixed (sunk in the short run) then the marginal product of capital does not equal its steady-state rental rate but rather its current shadow rental. That is, the user cost of capital in the Hall-Jorgenson formula should be multiplied not by the price of investment goods, which is the usual procedure, but by the shadow value of capital, marginal q. (The shadow rental also includes expected capital gains.)

This problem is not significant for estimates of returns to scale, however. for two reasons. First, as argued. quasi-fixity affects only the period-by-period computation of the input shares. not the growth rate of capital (or any other quasi-fixed input). Since these shares are constant to a first-order Taylor 
approximation, any errors caused by failure to track the movements of the shares is likely to be small. Second. mismeasurement of the rental rate of capital has its strongest effect on capital's share. But since the growth rate of capital is almost uncorrelated with the business cycle, errors in measuring capital's share are unlikely to cause significant biases in a study of cyclical productivity. Caballero and Lyons (1989) present simulations indicating that maximum biases from quasi-fixity are likely to be on the order of $3 \%$ of the estimated coefficients.

It is convenient to define a cost-weighted sum of primary inputs of capital and labor. Since this is the "value-added" analogue to $d x$, we call it $d x^{\prime}$. and define it as:

$$
d x^{\nu}=\left(\frac{c_{\underline{K}}}{c_{K}+c_{L}}\right) d k+\left(\frac{c_{L}}{c_{K}+c_{L}}\right) d i \text {. }
$$

One can also rewrite (A8) as:

$$
d y=\gamma \cdot\left[\left(1-c_{M}\right) d x^{V}+c_{M} d m\right]+d t
$$

One more tranformation will prove useful below. By subtracting $\gamma c_{\mathrm{M}} \mathrm{dy}$ from both sides and rearranging, we can write the previous equation as:

$$
d y=\left[\frac{\gamma\left(1-c_{M}\right)}{1-\gamma c_{M}}\right] d x^{v}+\left(\frac{\gamma c_{M}}{1-\gamma c_{M}}\right)(d m-d y)+\frac{d t}{1-\gamma c_{M}}
$$

Instead of gross output. many researchers use data on value added, where measures of real value added attempt to subtract from gross output the productive contribution of intermediate goods. Hence, gross output is shoes. while value added is "shoes lacking leather, made without power" (Domar 1961. p716). Despite its unintuitive nature, researchers use value added for at least two reasons. First, since sectoral value added sums to national output. it is a natural simplification for macroeconomists to focus, even at a sectoral level, on value added and primary inputs of capital and labor. Second, because national 
accounting data are widely distributed, data on sectoral value added tend to be better known than the gross-output data used to construct them.

The preferred way to measure output net of intermediate inputs is to create a Divisia index. The growth rate of the Divisia index of industry real value added dv is defined as

$$
d v \equiv \frac{\left(d y-s_{M} d m\right)}{\left(1-s_{M}\right)}=d y-\left(\frac{s_{M}}{1-s_{M}}\right)(d m-d y)
$$

Value added is like a partial Solow residual, subtracting intermediate growth from outpuit growth, weighted by the share of intermediate inputs in revenue. The second equality shows that if the materials-to-output ratio is constant, then value added grows at the same rate as gross output and intermediates.

Substituting from equation (All) for dy, we find:

$$
d v=\left[\frac{\gamma\left(1-c_{M}\right)}{1-\gamma \cdot c_{M}}\right] \cdot d x^{v}+\left[\frac{\gamma c_{M}}{1-\gamma c_{M}}-\frac{s_{M}}{1-s_{M}}\right](d m-d y)+\frac{d t}{1-\gamma c_{M}}
$$

Since $\gamma c_{M}$ equals $\mu s_{M}$. this equation can also be written as:

$$
d v=\left[\frac{\gamma \cdot\left(1-c_{M}\right)}{1-\gamma \cdot c_{M}}\right] \cdot d x^{\nu}+(\mu-1)\left[\frac{s_{M}}{\left(1-\mu s_{M}\right)\left(1-s_{M}\right)}\right] \cdot(d m-d y)+\frac{d t}{1-\gamma c_{M i}}
$$

If there are constant retums to scale and no markups, then the growth rate of value added equals the growth rate of primary inputs plus technological progress. That is, 


$$
d v=d x^{v}+\frac{d t}{\left(1-s_{M}\right)}
$$

One implication of equation (A15) is that if $s_{M}$ is constant. then as Hall (1990) notes, under competition and constant returns the productivity residual $\left(d v-d x^{\prime}\right)$ calculated from a Divisia index of value added is uncorrelated with any variable that neither causes productivity shifts, nor is caused by productivity shifts. In addition, $\mathrm{dx}^{\prime}$ can be calculated with either cost or revenue shares, since there are no profits. In the presence of markups, however. equation (A14) shows that the intensity of intermediate input use (dm-dy) directly affect value-added growth. Intuitively, value added is calculated by subtracting from gross output the productive contribution of intermediate goods, assuming that the elasticity of output with respect to intermediate inputs equals its revenue share. With markups, this elasticity exceeds its revenue share. Hence, some of the contribution of materials and energy is attributed to value added. As a result, the value-added productivity residual is correlated with any variable that is correlated with intermediategoods use, regardless of whether it is correlated with technology. Thus, Hall's argument that under constant returns the cost-based Solow residual should be invariant is true in gross-output data, but is not in general true with value-added data. It is, of course. true if markups equal 1 , or if intermediate inputs are always used in fixed proportions to output. In particular, note that if markups exceed 1, a rise in energy prices may well cause the intensity of energy use to fall, affecting the growth of value added.

As we noted in the text, the parameter of interest may not be the degree of returns to scale in gross output. Consider the following specialization of (Al):

$$
Y=G(V(K, L, \eta), H(M))
$$

Macroeconomists usually model sectoral production functions with a separable form as in (A16)--CobbDouglas, for example. There are three possible sources of increasing returns in $\mathrm{Y}$ : increasing returns in $\mathrm{V}$. increasing returns in $\mathrm{H}$, or increasing returns in how $\mathrm{V}$ and $\mathrm{H}$ are combined to produce $\mathrm{G}$. Examples of these different sources include overhead labor and capital, overhead intermediate inputs such as 
advertising. or declining marginal cost. Suppose one assumes that all returns to scale are in $\mathrm{V}$. One might hope that estimates of returns to scale with value-added data are estimates of the homogeneity of $\mathrm{V}$.

The sum of output elasticities $\gamma$ with respect to $K, L$, and $M$ is then

$$
\gamma=\frac{G_{V} V}{Y}\left(\frac{V_{K} K}{V}+\frac{V_{L} L}{V}\right)+\frac{G_{H} H}{Y} \frac{H_{M} M}{H}
$$

Let $\mathrm{G}$ be homogeneous of degree one in $\mathrm{V}$ and $\mathrm{H}$, and $\mathrm{H}$ be homogeneous of degree one in $\mathrm{M}$. Then $G_{V} V / Y$ equals $\left(1-G_{M} M / Y\right)$, and the first order conditions tell us that the output elasticity with respect to materials is $\gamma c_{M}$. Hence. we can rewrite this equation as

$$
\gamma=\left(1-\gamma c_{m}\right) \gamma^{v}+\gamma c_{M}
$$

The relationship between $\gamma^{\prime}$ and $\gamma$ is then:

$$
\gamma^{\nu}=\gamma\left(\frac{1-c_{M}}{1-\gamma c_{M}}\right)
$$

With increasing returns, value-added returns to scale $\gamma^{*}$ exceed gross-output returns to scale $\gamma$, since $\gamma$ is a weighted average of $\gamma^{\prime}$ and one. A key observation here is that in equation (A 14) above. the term multiplying $d x^{\prime \prime}$ just equals $\gamma^{\prime \prime}$.

One source of economic intuition for $\gamma^{v}$ is that under some circumstances. it correctly captures "economy-wide" returns to scale, as small increasing retums at the plant level translate into larger increasing returns for the economy overall. Suppose, for example, that final output is produced at the end of an infinite number of stages. At each stage a representative firm with returns to scale $\gamma$ uses all the output of the previous stage as intermediate input, and also uses primary inputs of capital and labor. Then the percent change in national income--the output of the last (nth) stage--is 


$$
\begin{aligned}
d y_{n} & =\gamma\left(1-c_{M}\right) d x_{n}^{\nu}+\gamma c_{M} \phi_{n-1} \\
& =\gamma\left(1-c_{M}\right) d x_{n}^{\nu}+\gamma c_{M} \gamma\left(1-c_{M}\right) d x_{n-1}^{\nu}+\left(\gamma c_{M}\right)^{2} d y_{n-2} .
\end{aligned}
$$

We can substitute into this equation for $d y_{n \cdot j}$ and let $j$ go to infinity. Since each firm is identical, $d x_{r}$ "is the same for al! $i$ as for the aggregate. This gives an infinite sum, which sums to $\gamma^{\prime}$ times the cost-shareweighted growth rate of aggregate primary inputs. Thus, $\gamma^{\prime}$ is plausibly the appropriate concept for calibrating the degree of returns to scale of the production function in a one-sector macroeconomic model.

Note that $\gamma^{\prime \prime}$ correctly captures the idea that small deviations from constant returns "cascade" in going from gross output to value-added. That is. if inputs rise in sectors with relatively large returns to scale in gross output, these sectors not only produce more goods to satisfy final demand for their own product, but produce more goods to use as intermediate inputs in producing other goods. Nevertheless, this derivation shows that there is a limit to how much the effects can cascade or build up.

Even if we want this value-added returns to scale, we still in general require data on intermediate inputs. The reason is that we do not observe $\mathrm{V}$ directly, but must infer it from observable gross output and intermediate inputs. Note that in equation (Al6), with the homogeneity assumptions we've made, the growth of productive value added, which we will denote $d v^{p}$, is implicitly defined as follows:

$$
d v^{P}=d y-\left(\frac{G_{M^{M}}}{G_{V} V}\right)(d m-d y)
$$

Comparing this to the equation defining standard value added $d v$, and substituting for the output elasticities with respect to materials and value-added, we can write dv as

$$
d v=d v^{P}+\left(\frac{\gamma s_{M}}{1-\gamma s_{M}}-\frac{s_{M}}{1-s_{M}}\right)(d m-d y) .
$$


This confirms the intuition we presented earlier about equations (A13) and (A14): The second term in those equations represents the difference between the growth rates of the standard measure of value added and a measure which is appropriate as a measure of production or net output.

Finally, substituting for the definition of $\gamma^{v}$ from equation (A19) into equation (A13), we find:

$$
d v=\gamma^{v} \cdot d x^{\nu}+\left[\frac{\gamma^{\nu} c_{M}}{1-c_{M}}-\frac{s_{M}}{1-s_{M}}\right](d m-d y)+\frac{d t}{1-\mu s_{M}} .
$$

If there are zero profits, then we can also write this as:

$$
d v=\gamma^{\nu} \cdot d x^{\nu}+\left(\gamma^{v}-1\right)\left[\frac{s_{M}}{1-s_{M}}\right](d m-d y)+\frac{d t}{1-\mu s_{M}}
$$

This is the equation we use in Section III of the paper when we derive our aggregation equations. 


\section{Appendix II \\ Data Sources and Methods}

We use unpublished data provided by Dale Jorgenson and Barbara Fraumeni on industry-level gross output and inputs of capital, labor, energy, and materials. These include data for 21 manufacturing industries and 13 non-manufacturing industries. ${ }^{2+}$ These sectoral accounts seek to provide accounts that are, to the extent possible. consistent with the economic theory of production. These data are available both with and without an adjustment for input quality. The quality adjustment essentially involves taking account of changes over time in input composition. Computers, for example, give a higher service flow per dollar than factories, since they depreciate faster. Similarly, engineers and janitors make a different marginal contribution to output. and one can use information on relative factor payments to adjust for the differences.

We calculate the variables we need from the Jorgenson data. The equations in the text are all derived in continuous time: in all cases, we approximate differentials with log differences and instantaneous shares with averages in periods $t$ and $t-1$. This Tornquist approximation is exact if the underlying production functions are translog; otherwise, they provide a flexible second-order approximation to any functions.

To estimate the required payments to capital, we follow Hail and Jorgenson (1967), Hall (1990), and Caballero and Lyons (1992), and compute a series for the user cost of capital $r$. The required payment for any type of capital. $P_{K} K$, is then $r \pi^{K} K$, where $\pi^{\wedge} K$ is the current-dollar value of the stock of this type of capital. In each sector. we use data on the current value of the 50 types of capital. plus land and

24 The manufacturing industries match the two-digit classification, except that transport equipment (SIC 37) is divided into "motor vehicles" (SIC 371) and "other transport equipment." The nonmanufacturing industries comprise agriculture. metal mining, coal mining, oil and gas extraction. nonmetallic mining. construction, transportation, communications, electric utilities, gas utilities. trade. financeinsurance-real-estate, and services. 


\section{All}

inventories. distinguished by the BEA in constructing the national product accounts. Hence, for each of these 52 assets, we compute the user cost of capital as

$$
r_{s}=\left(\rho+\delta_{s}\right) \frac{\left(1-I T C_{s}-\tau \cdot d_{s}\right)}{(1-\tau)}, s=1 \text { to } 52 .
$$

$\rho$ is the required rate of return on capital. For each asset, $\delta_{s}$ is the depreciation rate, ITC $\mathrm{s}_{s}$ is the investment tax credit. and $d_{s}$ is the present value of depreciation allowances. $\tau$ is the corporate tax rate. We assume that the required retum $\rho$ equals the dividend yield on the S\&P 500. We obtained unpublished data on ITC,$d_{s}$, and $\tau$ from Dale Jorgenson.

We estimate that the typical industry has an average profit rate of about 3 percent. Given uncertainty about whether the dividend yield appropriately captures the cost of funds, we have experimented with several alternative measures of the capital cost, as discussed in Basu and Fernald (1995a). Even assuming zero profits, so that revenue and cost shares are equal, has little effect on our results. This is unsurprising, since economic profits do not appear large in any of our measures.

We create aggregates as Divisia indices over the underlying industries. Note that aggregate gross output suffers substantial double counting from the expenditure side of the national accounts. If our interest is on the production side-for estimating returns to scale, for example-then aggregation effects are a significant issue but double counting is not. 


\section{A12}

\section{Appendix III \\ Are the Hall-Ramey Instruments Valid?}

This appendix suggests that they are not. because they are correlated with aggregation effects. Hence, while demand side instruments are likely to be valid at a firm level, they do not appear to be valid at higher levels of aggregation. This appendix presents the results cited in Section IV.

For each level of aggregation, we calculate the gross-output aggregation term $R$ and the valueadded terms $\left(\mathrm{R}^{\prime}+\mathrm{I}\right)$, defined in Section III. In aggregate data, these terms constitute part of the regression disturbance term. We regress these aggregation terms on each of the Hall-Ramey instruments: the tables below present marginal significance levels. as in Hall (1990, Tables 5.1 and 5.2). If the instruments are valid instruments, uncorrelated with the disturbance term, then it is necessary that they be uncorrelated with the aggregation terms. (It is of course not sufficient. As discussed in the text, the instruments may be invalid for reasons other than aggregation biases. Moreover, even if the instruments affect reallocations across industries, we may not detect this effect statistically if the standard errors are large.)

To calculate the aggregation terms, we need industry level estimates of returns to scale. If the instruments are valid, one wants to use the instruments to estimate the industry returns to scale. If the instruments are not valid, of course. then these industry estimates may also be invalid. (Even if there is feedback from technology shocks to input growth, so that OLS is biased, there is no reason to expect this to lead the calculated realiocation terms to be correlated with the instruments.) We calculate these terms both ways: Table Al shows results using the UNINSTRUMENTED estimates of industry paramers, while Table A2 shows results using the INSTRUMENTED estimates.

The instruments are the current and once-lagged value of (i) the growth rate of the world price of oil (oil); (ii) the growth rate of government defence spending deflated by the GDP deflator (gdef): and (iii) the political party of the president/party in power (pip). 
For the change in the world price of oil, we can usually reject the null that the instruments are not associated with aggregation effects. In Table A2 for the private economy as a whole, for example, the coefficient on the current oil price is significantly negative at the 0.001 level; the coefficient on the lagged change is significantly negative at the 0.01 level for value-added and the 0.05 level for gross output. Government defence spending positively affects reallocations for manufacturing durables, but is otherwise insignificant. as is the political party of the president. These results thus verify the empirical importance of the theoretical point that the instruments we (and many others) use are not valid as instruments at an aggregate level. 
Table A1

Dependent Variable: Estimated Gross Output Aggregation Terms (Uninstrumented Estimate) Entries are marginal significance levels for regression on each of the instruments

\begin{tabular}{|l|l|l|l|l|l|}
\hline & $\begin{array}{l}\text { Private } \\
\text { Economy }\end{array}$ & $\begin{array}{l}\text { Non - } \\
\text { Manufact. }\end{array}$ & Manufact. & $\begin{array}{l}\text { Durables } \\
\text { Manufact. }\end{array}$ & $\begin{array}{l}\text { Non-Dur. } \\
\text { Manufact. }\end{array}$ \\
\hline oil & $0.034^{*}$ & $0.012^{*}$ & 0.113 & 0.455 & $0.019^{*}$ \\
\hline oil(-1) & $0.015^{*}$ & $0.021^{*}$ & 0.181 & 0.600 & 0.056 \\
\hline gdef & 0.382 & 0.587 & 0.189 & $0.001^{* *}$ & 0.945 \\
\hline gdef(-1) & 0.760 & 0.495 & 0.847 & 0.579 & 0.185 \\
\hline pip & 0.766 & 0.311 & 0.887 & 0.107 & 0.711 \\
\hline pip(-1) & 0.904 & 0.549 & 0.730 & 0.309 & 0.689 \\
\hline
\end{tabular}

Dependent Variable: Estimated Value Added Aggregation Terms (Uninstrumented Estimate)

Entries are marginal significance levels for regression on each of the instruments

\begin{tabular}{||l|l|l|l|l|l||}
\hline & $\begin{array}{l}\text { Private } \\
\text { Economy }\end{array}$ & $\begin{array}{l}\text { Non - } \\
\text { Manufact. }\end{array}$ & Manufact. & $\begin{array}{l}\text { Durables } \\
\text { Manufact. }\end{array}$ & $\begin{array}{l}\text { Non-Dur. } \\
\text { Manufact. }\end{array}$ \\
\hline oil & 0.064 & 0.104 & 0.049 & 0.430 & 0.507 \\
\hline oil(-1) & $0.021^{*}$ & $0.013^{*}$ & 0.293 & 0.860 & $0.014^{*}$ \\
\hline gdef & 0.367 & 0.685 & 0.063 & $0.001^{*}$ & 0.663 \\
\hline gdef(-1) & 0.829 & 0.404 & 0.634 & 0.730 & 0.970 \\
\hline pip & 0.689 & 0.341 & 0.739 & 0.065 & 0.560 \\
\hline pip(-1) & 0.955 & 0.689 & 0.911 & 0.276 & 0.351 \\
\hline
\end{tabular}

* Significant at the 5 percent level.

** Significant at the 1 percent level 
Table A2

Dependent Variable: Estimated Gross Output Aggregation Terms (Instrumented Estimate) Entries are marginal significance levels for regression on each of the instruments

\begin{tabular}{||l|l|l|l|l|l||}
\hline & $\begin{array}{l}\text { Private } \\
\text { Economy }\end{array}$ & $\begin{array}{l}\text { Non - } \\
\text { Manufact. }\end{array}$ & Manufact. & $\begin{array}{l}\text { Durables } \\
\text { Manufact. }\end{array}$ & $\begin{array}{l}\text { Non-Dur. } \\
\text { Manufact. }\end{array}$ \\
\hline oil & $0.000^{* *}$ & $0.000^{* *}$ & 0.105 & 0.267 & 0.060 \\
\hline oil(-1) & $0.036^{*}$ & $0.007^{* *}$ & 0.233 & 0.603 & 0.265 \\
\hline gdef & 0.763 & 0.924 & 0.523 & $0.006^{* *}$ & 0.400 \\
\hline gdef(-1) & 0.191 & 0.262 & 0.577 & 0.779 & 0.070 \\
\hline pip & 0.334 & 0.300 & 0.809 & 0.439 & 0.370 \\
\hline pip(-1) & 0.570 & 0.372 & 0.538 & 0.794 & 0.767 \\
\hline
\end{tabular}

Dependent Variable: Estimated Value Added Aggregation Terms (Instrumented Estimate) Entries are marginal significance levels for regression on each of the instruments

\begin{tabular}{||l|l|l|l|l|l||}
\hline & $\begin{array}{l}\text { Private } \\
\text { Economy }\end{array}$ & $\begin{array}{l}\text { Non - } \\
\text { Manufact. }\end{array}$ & Manufact. & $\begin{array}{l}\text { Durables } \\
\text { Manufact. }\end{array}$ & $\begin{array}{l}\text { Non-Dur. } \\
\text { Manufact. }\end{array}$ \\
\hline oil & $0.001^{* *}$ & $0.014^{*}$ & $0.015^{*}$ & 0.247 & 0.168 \\
\hline oil(-1) & $0.005^{* *}$ & $0.002^{* *}$ & 0.250 & 0.777 & $0.005^{* *}$ \\
\hline gdef & 0.797 & 0.780 & 0.323 & $0.021^{*}$ & 0.547 \\
\hline gdef(-1) & 0.241 & 0.193 & 0.962 & 0.826 & 0.790 \\
\hline pip & 0.377 & 0.525 & 0.986 & 0.250 & 0.550 \\
\hline pip(-1) & 0.428 & 0.586 & 0.974 & 0.734 & 0.415 \\
\hline
\end{tabular}

* Significant at the 5 percent level.

** Significant at the 1 percent leve! 


\section{International Finance Discussion Papers}

IFDP

Number
Tities

1996

Returns to Scale in U.S. Production: Estimates and Implications

545 Mexico's Balance-of-Payments Crisis: A Chronicle of Death Foretold

544 The Twin Crises: The Causes of Banking and Balance-of-Payments Problems

543 High Real Interest Rates in the Aftermath of Disinflation: Is it a Lack of Credibility?

Precautionary Portfolio Behavior from a Life-Cycle Perspective

Using Options Prices to Infer PDF's for Asset Prices: An Application to Oil Prices During the Gulf Crisis

Monetary Policy in the End-Game to Exchange-Rate Based Stabilizations: The Case of Mexico

Comparing the Welfare Costs and the Initial Dynamics of Alternative Temporary Stabilization Policies

Long Memory in Inflation Expectations: Evidence from Intemational Financial Markets

Using Measures of Expectations to Identify the Effects of a Monetary Policy Shock

536 Regime Switching in the Dynamic Relationship between the Federal Funds Rate and Innovations in Nonborrowed Reserves

535 The Risks and Implications of Exiernal Financial Shocks: Lessons from Mexico

534 Currency Crashes in Emerging Markets: An Empirical Treatment

Author(s)

Susanto Basu

John G. Fernald

Guillermo A. Calvo

Enrique G. Mendoza

Graciela L. Kaminsky

Carmen M. Reinhart

Graciela L. Kaminsky

Leonardo Leiderman

Carol C. Bertaut

Michael Haliassos

William R. Melick

Charles P. Thomas

Steven B. Kamin

John H. Rogers

Martin Uribe

Joseph E. Gagnon

Allan D. Brunner

Chan Huh

Edwin M. Truman

Jeffrey A. Frankel Andrew K. Rose

Please address requests for copies to International Finance Discussion Papers, Division of International Finance, Stop 24, Board of Governors of the Federal Reserve System. Washington, D.C. 20551 . 


\section{International Finance Discussion Papers}

IFDP

Number

Titles

Author(s)

1996

533 Regional Pattems in the Law of One Price:

Charles Engel The Roles of Geography vs. Currencies

John H. Rogers

1995

532 Aggregate Productivity and the Productivity of Aggregates

Susanto Basu

John G. Fernald

531 A Century of Trade Elasticities for Canada. Japan, and the United States

Jaime Marquez

$530 \quad$ Modelling Inflation in Australia

Gordon de Brouwer Neil R. Ericsson

529 Hyperinflation and Stabilisation: Cagan Revisited

Marcus Miller

Lei Zhang

528 On the inverse of the Covariance Matrix in Portfolio Analysis

Guy V.G. Stevens

526 Uncertainty, Instrument Choice, and the Uniqueness of Nash Equilibrium: Microeconomic and Macroeconomic Examples

Dale W. Henderson

Ning S. Zhu

525 Targeting Inflation in the 1990s: Recent Challenges

524 Economic Development and Intergenerational Economic Mobility

Richard T. Freeman Jonathan L. Willis

Murat F. Iyigun

523 Human Capital Accumulation, Fertility and Growth: A Re-Analysis

Murat F. lyigun

522 Excess Retums and Risk at the Long End of the Treasury Market: An EGARCH-M Approach

Allan D. Brunner David P. Simon

521 The Money Transmission Mechanism in Mexico

Martina Copelman Alejandro M. Werner

520 When is Monetary Policy Effective?

John Ammer

Allan D. Brunner

519 Central Bank Independence, Inflation and

Prakash Loungani Growth in Transition Economies

Nathan Sheets 